\title{
CSHP Professional Practice Conference 2014: Poster Abstracts / Conférence sur la pratique professionnelle 2014 de la SCPH : Résumés des affiches
}

Sunday, February 2, 2014 • Dimanche 2 février 2014

Facilitated Poster Sessions: Discussion of original research, award-winning projects, and pharmacy practice projects

Séance animée de presentations par affiches: Discussions sur des projets de recherche originale, des projets primés et des projets dans le domaine de la pratique pharmaceutique

\section{Education}

1. Do Learning Styles of Pharmacy Practice Residents Change When They Enter Practice?

2. Implementation and Assessment of a Continuous Pharmacy Student Clinical Role in a Hemodialysis Unit

3. Institutional Pharmacists' Perspectives on Precepting: A Comprehensive Province-Wide Study

4. Assessment of the Effect of Behavioral Change Strategies on Knowledge Translation and Interventions from Disease State Education Modules: DSEM-KT Study

5. Accuracy of Medication Histories Documented by Pharmacy Students versus Health Care Professionals

Clinical 1

1. Retrospective Analysis of the Implementation Success of an Antimicrobial Stewardship Program in a Community Hospital Without an Infectious Disease Physician

2. Risk Factors of Adverse Drug Reaction-Related Hospitalizations among Seniors, 2006 to 2011

3. Chemotherapy-Induced Nausea and Vomiting in Children Receiving High Dose Methotrexate with or without Vincristine: Preliminary Results

4. Safe Swallowing of Oral Liquid Medications in Patients with Dysphagia: A Patient Quality and Safety Initiative

5. Systematic Approach to Evaluate Hazardous Antineoplastic Drugs by a Provincial Healthcare Organization (award—see page 84)

Clinical 2

1. Evaluation of a Secondary Stroke Prevention Checklist Implemented on a Stroke-Medicine Unit in a Community Teaching Hospital

2. Losartan-induced Autoimmune Hepatoxicity: A Case Report

3. Venous Thromboembolism Prophylaxis in Long Term Care: A Prevalence Chart Review

4. Patterns and Predictors of Use of Oral Anticoagulants for Atrial Fibrillation

5. Aluminum Exposure from Calcium Gluconate 10\% Injection in Neonates Receiving Parenteral Nutrition

Professional Practice

1. Comparison of the Level of Conformity between the Medication Management Standards of Accreditation Canada and the Results of the Hospital Pharmacy in Canada Report

2. The Role of Clinical Informatics in Improving the Assessment of Venous Thromboembolism Risk and Prophylaxis

3. How Do Local, Provincial and National Perspectives on Clinical Key Performance Indicator Critical Activity Areas Compare?

4. The Role of Online/Smartphone Applications in Type II Diabetes Management: A Qualitative Study

5. Laboratory Test Ordering by Pharmacists in Canada: A Nationwide Study of Policies and Practices

\section{Monday, February 3, 2014 • Lundi 3 février 2014}

1. National Canadian Venous Thromboembolism (VTE) Prevention Audit Day: Design and Results

2. Improving Influenza Vaccination Uptake in the Progressive Care Unit of a Community Teaching Hospital
3. Appropriateness of Using Alternate Oral Anticoagulants in Poorly Controlled Warfarin Patients

4. Personalized Medicine: Teaching Strategies for a Novel Clinical Pharmacy Residency Rotation

5. Stroke Prediction in Atrial Fibrillation: Meta-analysis of the Predictive Performance of the CHADS and CHADS -VASc Clinical Prediction Rules

6. Development of Guidelines for Safe Management of Antithrombotic Medications Prior to Elective Surgical and Diagnostic Procedures in a Community Hospital Setting

7. Opportunities to Enhance Institutional Experiential Education in British Columbia: Learner Perspectives

8. Exploring Innovative Institutional Learner-Preceptor Models across Health Disciplines: A Systemic Review

9. Patient Medication Education at Discharge: A Multidisciplinary Team Based Approach (TEACH)

10. How Do National Clinical Pharmacy Key Performance Indicators Align With Top-Ranked Consensus Selection Criteria?

11. Handbook for a Pilot Study to Reduce Potential Hospitalizations due to Preventable Drug-Drug Interactions

12. What Are the Appropriate Clinical Pharmacy Key Performance Indicators for Hospital Pharmacists?

13. Démarche pour la mise à niveau d'un secteur de soins pharmaceutiques : le cas de la chirurgie pédiatrique

14. Stability of Clobazam $1 \mathrm{mg} / \mathrm{mL}$ in Extemporaneously Compounded Oral Suspensions Using Oral Mix Vehicle in PET, PVC, Glass Bottles and Plastic Unit-Dose Syringes

15. Stability of Domperidone $5 \mathrm{mg} / \mathrm{mL}$ in Extemporaneously Compounded Suspensions Using Oral Mix Vehicle in PET, PVC, Glass Bottles and Plastic Oral Unit-Dose Syringes

16. IV to PO Stepdown Interventions in a Community Hospital Without an Infectious Disease Physician

17. Update of the Canadian Labels for Antipsychotic Drugs Following a Review of the Evidence on the Risk of Venous Thromboembolism Associated with the Use of These Medications

18. Pharmacists Joining a Multi-Disciplinary Specialty Private Practice

19. Impact and Role of Pharmacists in Cystic Fibrosis

20. Evaluation of a Change in Clinical Pharmacist Practice Model in a Community Hospital

21. Médias sociaux, comportements en ligne et pharmaciens : lignes directrices et réflexions

22. Experience with Dexmedetomidine in a Medical Intensive Care Unit at a Community Teaching Hospital

23. Adherence to Hospital Sepsis Treatment Guidelines

\section{Tuesday, February 4, 2014 • Mardi 4 février 2014}

1. Drug Shortages in Health Care Institutions: Perspectives in Early 2014

2. Adverse Drug Reaction-Related Hospitalizations among Seniors, 2006 to 2011

3. Development of a Process to Ensure Timely Home Medication Access for Patients Awaiting Admission in the Emergency Department

4. Reduction of Polypharmacy in a Rehabilitation and Progressive Care Unit

5. What Doses Should Our Chemotherapy Robot Prepare?

6. The Effect of Residual Renal Function and Other Patient Factors on Gram Positive Peritonitis Outcomes

7. Can a Collective Community Mental Health Smoking Cessation Program Reduce Cigarette Consumption?

8. Comparison among Atorvastatin, Rosuvastatin and Pravastatin with Focus on Efficacy and Safety Profiles 


\section{PPC 2014 POSTER ABSTRACTS / RÉSUMÉS DES AFFICHES DE LA CPP 2014}

9. The Path Forward: Solutions from a Province-Wide University Health Authority Engagement Initiative

10. Successful Medication Reconciliation Implementation in a Multi-site Acute Care Facility

11. Facilitation of Medication Reconciliation by a Clinical Registered Pharmacy Technician in an Orthopedic Unit of a Community Hospital: A Pilot Project

12. Impact of a Multidisciplinary Program on Smoking Cessation Medication Use Patterns

13. Impact des données probantes sur l'implantation des codes-barres en milieu hospitalier

14. Impact des données probantes sur l'implantation des pompes intelligentes en milieu hospitalier

15. Impact des données probantes sur l'implantation de la réconciliation médicamenteuse en milieu hospitalier

16. Prescribing Patterns and Safety of Intramuscular Olanzapine in Hospitalized Elderly Patients

17. Optimizing Pharmacotherapy in a Geriatric Day Hospital: A Medication Use and Cost Analysis

18. Home Care Pharmacy Services: A Demonstration Project

19. Impact des données probantes sur l'implantation des prescripteurs électroniques en milieu hospitalier

20. Impact des données probantes sur l'implantation d'aides à la décision clinique pour les prescripteurs électroniques en milieu hospitalier

21. Impact of an "Avoid-Heparin" Quality Improvement Program on the Incidence, Clinical Consequences and Resource Use Associated with Heparin-Induced Thrombocytopenia (HIT) (award—see page 84)

\section{CSHP 2015}

CSHP 2015 is a quality program that sets out a vision of pharmacy practice excellence in the year 2015. Through this project, CSHP challenges hospital pharmacists to reach measurable targets for $36 \mathrm{objec}-$ tives grouped under 6 goals, all aimed toward the effective, scientific, and safe use of medications and meaningful contributions to public health. CSHP 2015 applies to inpatients and outpatients, community and hospital pharmacists, and all practice settings. Posters identified with a "CSHP 2015" logo are those judged by the CSHP 2015 Steering Committee to be particularly relevant to one or more of the 36 objectives.

\section{SCPH 2015}

Le projet SCPH 2015 est un programme axé sur la qualité qui propose une vision de l'excellence en pratique pharmaceutique en l'an 2015. Au moyen de ce projet, la SCPH met les pharmaciens d'établissements au défi d'atteindre les cibles mesurables de 36 objectifs répartis entre 6 buts, visant tous l'utilisation efficace, scientifique et sûre des médicaments ainsi que des contributions significatives à la santé publique. Le projet SCPH 2015 s'applique aux patients hospitalisés et externes, aux pharmaciens d'hôpitaux et communautaires, et à tous les milieux de pratique. Les affiches marquées du logo "SCPH 2015 " sont celles que le Comité directeur du projet SCPH 2015 a jugé particulièrement appropriées à l'un ou l'autre des 36 objectifs.

The texts of poster abstracts are published exactly as submitted by the authors and have not undergone any copyediting by the Canadian Journal of Hospital Pharmacy. I Le Journal canadien de la pharmacie hospitalière n’a pas soumis le texte des résumés des affiches à une révision linguistique et les publie ici tels que remis par les auteurs.

\section{Do Learning Styles of Pharmacy Practice Residents Change When They Enter Practice?}

Peter Loewen ${ }^{l, 2}$, Janice Yeung ${ }^{1,2}$, Anca Jelescu-Bodos', Torey Lau ${ }^{l}$ ${ }^{1}$ Faculty of Pharmaceutical Sciences, The University of British Columbia, Vancouver, $B C$

${ }^{2}$ Lower Mainland Pharmacy Services, Vancouver, BC

Rationale: Learning styles (LS) of medical residents change over time from the more passive Assimilator toward more active preferences like Accommodator or Converger. We have shown pharmacy residents to be predominantly Assimilators at the start of their residency program. Whether learning styles of pharmacy residents change after they enter practice has never been studied.

Objective: To describe the evolution of learning styles of pharmacy residents as they transition from residency into practice.

Study Design and Methods: Prospective observational survey and semi-structured interviews. A complete provincial cohort of former pharmacy residents $(n=28)$ who had their LS characterized during their residency and were now 1 year post-residency were invited to repeat the Pharmacists' Inventory of Learning Styles (PILS). Interviews were administered to consenting participants to gain additional insights.

Results: 27 residents (96\%) completed the PILS survey and 16 (59\%) completed the interview. 13 (48\%) changed their dominant LS and 20 (74\%) changed their secondary LS. Six (22\%) participants did not change either LS. The overall proportion of dominant Assimilators (59\%) and Convergers (26\%) remained similar to baseline (52\% and $26 \%$, respectively), meaning participants had adopted and abandoned different learning styles in similar numbers. Change in LS was associated with receiving preceptor training $(\mathrm{p}<0.05)$. Of the 12 preceptors interviewed, $58 \%$ stated that they had adjusted their teaching practices based on knowledge of their LS.

Conclusions: Change in dominant and/or secondary learning style is common after 1 year in practice compared to during pharmacy practice residency. There is no overall direction to the shifts, however, with residents transitioning in and out of more active learning styles with similar frequency. Overall after a year in practice, the cohort of former residents we studied remained mostly Assimilators, who prefer passive learning approaches. These results contrast with medical students, who adopt more active preferences like Accommodator.

\section{Implementation and Assessment of a Continuous Pharmacy Student Clinical Role in a Hemodialysis Unit}

Karen Cameron, Marisa Battistella, Colette Raymond

University Health Network and Leslie Dan Faculty of Pharmacy,

University of Toronto, Toronto, $O N$

Rationale: In 2011, the hemodialysis (HD) pharmacist role at a 300 patient tertiary care HD unit changed to clinician scientist, necessitating restructuring the way clinical pharmacy services were delivered. This change corresponded with availability of four month co-op students from University of Waterloo (UW) and summer students from University of Toronto (UT).

Description: Many core clinical pharmacist activities are ideally suited to be performed by pharmacy students in a supervisor-teacher model. Experiences in hospital settings/direct patient care areas are 
sought after as opportunities to practice core skills. A pharmacy student job description was created.

Implementation: Since January 2012, four UW and one UT pharmacy student have carried out the role. One summer term the role was split with two volunteer UT students. One term (winter 2013) did not have a student. Student activities include: medication reconciliation, anticoagulation monitoring, antibiotic assessment and review, resolution of drug coverage issues, responding to drug information questions and monthly blood work review. Students also perform pharmacotherapy work ups (select patients) and assist with research projects and medical writing. The outgoing student trains the subsequent student and participates in near-peer teaching with students on experiential rotations.

Evaluation: Four jobs were posted for UW co-op students and one for UT students. Twenty seven to forty five students applied for each one position, indicating high interest in this role. An anonymous evaluation survey was administered to all participating students (survey monkey) as well as HD unit medical and nursing staff. Students highly valued the experience. HD team members appreciate increased accessibility of pharmacy staff.

Importance: This model may be transferable to other HD units or similar practice sites with increasing patient numbers, changing pharmacist responsibilities or increased number of advanced pharmacy practice experiential learners.

\section{Institutional Pharmacists' Perspectives on} Precepting: A Comprehensive Province-Wide Study

Michael Legal, Donna Rahmatian, Kyle Collins, Patricia Gerber, Angela Kim-Sing, Peter J Zed, Peter S Loewen

Faculty of Pharmaceutical Sciences, The University of British Columbia, Vancouver, BC

Rationale: It is a challenge to provide sufficient quantities of high quality institutional experiential placements for learners. In recent years, this issue has become increasingly acute in pharmacy due to curricular and program changes in Canada. In British Columbia a comprehensive multi-stakeholder engagement project was undertaken to identify solutions. This report describes the pharmacist engagement portion of the project.

Objectives: To characterize the perspectives of institutional pharmacists, identify potential solutions to capacity challenges and to find ways to better support preceptors and learners.

Methods: Pharmacist perspectives were gathered using a mixed methods approach. An online survey was deployed to all hospital pharmacists in BC. In addition, focus groups and structured interviews were conducted across the province. The survey utilized a combination of likert, ranking, multiple-answer, and open field responses. Focus groups and interviews were recorded and the resulting transcripts were analyzed using qualitative methods and iterative coding to identify major themes.

Results: A total of 233 pharmacists responded to the survey and over 200 participated in the focus groups and interviews. Pharmacists indicated that teaching is an important professional role and they appear to be intrinsically motivated to precept. Workload, lack of time to teach, inadequate staffing, lack of faculty support and unprepared learners were major barriers. Participants identified a need to strengthen the curriculum to increase learner exposure to institutional practice and to enhance their practice-readiness. Human resource support was the most desirable solution for workload issues. Multi-learner models were viewed favourably as a capacity solution but increased teaching workload and limited physical space were concerns. A more robust relationship with the faculty was also desired.

Conclusions: This project highlighted some key challenges faced by preceptors and suggests some possible solutions. These solutions will require collaboration and commitment by all parties to ensure success.

\section{Assessment of the Effect of Behavioral Change Strategies on Knowledge Translation and Interventions from Disease State Education Modules: DSEM-KT Study}

Richard Slavik, Sarah Murray, Sean Gorman, Nicole Bruchet, Dawn Dalen, Brett Hamilton

Interior Health Authority, Kelowna, BC

Rationale: Pharmacists require continuous professional development (CPD) to resolve drug related problems (DRPs) for patients with priority disease states. To promote pharmacist CPD, eight 4-week disease state education modules (DSEMs) were delivered from January 2009 to December 2011. After each DSEM, lists of disease-specific key pharmacist interventions (DSEM KPI) - evidence-based interventions proven to reduce mortality, morbidity, or health care utilization, were developed to guide pharmacists' interventions. A recent study showed that DSEMs improved process of care measures by pharmacists, but not for the subgroup of patients with heart failure (HF).

Objective: To determine if the application of multifaceted professional behavioral change strategies improves knowledge translation of HF therapeutics for clinical pharmacists and improves processes of care measures for HF patients.

Methods: Prospective quasi-experimental, one group, pre/post study evaluating proven multifaceted behavioral change strategies on clinical pharmacists from July 1, 2012 to July 31, 2013. The primary outcome was the change in proportion of pharmacist-resolved HF DRP/DSEM DRP. Secondary outcomes included the change in proportion of pharmacist-resolved HF KPI/DSEM KPI, the change in quiz scores evaluating clinical pharmacists' knowledge of HF therapeutics, and the primary outcome analyzed by site.

Results: The proportion of pharmacist-resolved HF DRP/DSEM DRP increased from $9.6 \%$ to $15.3 \%$; (relative risk increase [RRI] $59.7 \%, 95 \%$ confidence interval [CI] 43.4-78.0\%). The proportion of pharmacist-resolved HF KPI/DSEM KPI increased from $4.4 \%$ to 9.7\% (RRI 119.1\%, 95\% CI 82.3-163.6\%). Knowledge translation quiz scores increased from 16.8/20 (84\%) to 18.9/20 (95\%), $\mathrm{p}<0.05$.

Conclusions: There was a statistically significant increase in knowledge translation of HF therapeutics for clinical pharmacists and a statistically significant increase in the proportion of resolved HF DRP/DSEM DRP and HF KPI/DSEM KPI for HF patients. Bundled behavioral change strategies should be provided after future DSEMs to improve knowledge translation for pharmacists and care of patients with priority diseases.

\section{Accuracy of Medication Histories Documented by Pharmacy Students versus Health Care Professionals}

N M Facca ${ }^{I}, S$ Ahrari ${ }^{1,2}$, J Stovel ${ }^{l, 3}, J$ A Seabrook ${ }^{3,4}$, S Jansen ${ }^{l}$

${ }^{1}$ London Health Sciences Centre, London, ON

${ }^{2}$ University of Waterloo, Waterloo, $\mathrm{ON}$

${ }^{3}$ Western University, London, $O N$

${ }^{4}$ Children's Health Research Institute, London, ON 
Rationale: A multi-site teaching hospital has successfully implemented a mixed model of medication reconciliation across all in-patient units. Accurate medication histories reduce medication errors and prevent adverse drug events. Pharmacists have been shown to obtain more accurate medication histories than other health care professionals. Due to lack of pharmacist resources, pharmacy students were trained to complete medication histories in the pre-admission clinic at this facility to support medication reconciliation workflow.

Objective: To compare the number and types of medication discrepancies in the best possible medication history captured by a pharmacy student compared to other health care professionals.

Methods: This quasi-experimental retrospective study took place from March to April 2013. Patients included in the study were admitted for orthopedic surgery and were required to have had the medication history reviewed by at least one other health care professional. A trained pharmacy student documented the medication history in the pre-admission clinic, whereas the first health care professional documented medication histories upon patient presentation to the emergency department. An independent investigator reviewed charts to detect discrepancies between the initial and reviewed medication histories. Unintentional discrepancies were reviewed with a clinical pharmacist.

Results: There were 38 medication discrepancies found in the 50 medication histories done by the pharmacy student (with 37/38 classified as unintentional discrepancies) versus 151 found in the 50 medication histories done by the health care professional (with 133/151 unintentional discrepancies). The difference in unintentional discrepancies between the groups was statistically significant $(\mathrm{p}<0.001)$.

Conclusion: Pharmacy students in the pre-admission clinic documented medication histories containing fewer discrepancies than staff in the emergency department and are, therefore, a viable hospital resource to help improve patient safety and continuity of patient care.

\section{Retrospective Analysis of the Implementation Success of an Antimicrobial Stewardship Program in a Community Hospital Without an Infectious Disease Physician}

Mark Taylor, Andrea Wist, Gayathri Radhakrishnan, Rebecca Strutchbury, Joel Varsava, Alicia Oesch

Bluewater Health, Sarnia, ON

Rationale: There is a paucity of data on the impact of the implementation of an Antimicrobial Stewardship Program in community hospitals without an Infectious Disease physician. This report of the Bluewater Health (BWH) Stewardship Program, with emphasis on the pharmacist, serves as a sustainable template for community hospitals to satisfy the Accreditation Standards.

Description: BWH is a 326 bed community hospital without an Infectious Disease Physician. Our Stewardship program is designed based on the Infectious Disease Society of America (IDSA) guidelines. We used the 2 IDSA proactive models: Prospective audit with intervention and Formulary Restriction.

Implementation Steps: Our process included the following steps:

1. Creation of a BWH antimicrobial guideline and antibiogram in 2011.

2. Implementation of a "restricted" antimicrobial selection process based on cost, adverse events, negative patient outcome risks.

3. Monitoring of antimicrobials' Defined Daily Dosing (DDD)

4. Monitoring of Clostridium Difficile infection rates.
Evaluation: The Stewardship program was evaluated using qualitative and quantitative parameters. Quantitative parameter(s) include: Number of antimicrobial orders which necessitated Clinical Interventions initiated by pharmacists (Table 1), trends in Defined Daily Dose (DDD) of 2 broad spectrum antimicrobials, trends in Clostridium Difficile rates. Qualitative parameter(s) include: Pharmacists' self perceived level of comfort and competency regarding antimicrobials. On a Likert Scale of 1 to 4, pharmacists rated their competency and comfort as 1.42 (pre implementation) and 1.89 (post implementation)

Table 1: Summary of Quantitative parameters for Clinical Interventions (for the table that goes with this abstract, please see Abstract Appendix, available online at www.cjhp-online.ca/index.php/cjhp/ issue/view/100/showToc)

Relevance to Practice: By highlighting our strategies, we will be adding to the current paucity of literature that surrounds antimicrobial stewardships in community hospitals without Infectious Disease Physicians.

\section{Risk Factors of Adverse Drug Reaction-Related Hospitalizations among Seniors, 2006 to 2011}

Michele Arthur, Michael Gaucher

Canadian Institute for Health Information, Ottawa, ON

Rationale: Adverse drug reactions (ADRs) are defined by the World Health Organization as adverse effects of a drug that was properly administered in the correct dose, for therapeutic or prophylactic use. Seniors are at greater risk for ADRs, as well as other types of drugrelated adverse events, due to the number of drugs they take, their higher prevalence of certain chronic conditions and age-related changes in the body.

Objectives: This analysis examined potential risk factors for ADR hospitalizations and compared seniors' drug therapy pre-admission and post-discharge to see if ADR-related hospitalizations led to changes in drug therapy.

Study Design and Methods: This analysis used hospital discharge data from the Discharge Abstract Database and drug claims data from the National Prescription Drug Utilization Information System Database to assess potential risk factors for ADR hospitalizations among seniors on public drug programs in Alberta, Manitoba and P.E.I.

Results: The number of drugs was the most significant risk factor, with seniors taking 15 or more drugs being 6.4 times more likely than seniors taking fewer than 5 drugs to have been hospitalized for an ADR. Other factors associated with hospitalizations for ADRs were age and hospitalizations in the previous year. The relationship between new drug starts and ADR-related hospitalizations varied by drug class. Of seniors hospitalized for an opioid-related ADR, 33.2\% started taking an opioid within 30 days of hospitalization, while only $28.2 \%$ of seniors hospitalized for an anticoagulant-related ADR started an anticoagulant within a year of hospitalization.

Conclusion: Although it is often necessary for seniors to take multiple drugs to manage their chronic conditions, regular medication reviews can help reduce the risk of adverse events including drug interactions. A high proportion of the hospitalizations related to anticoagulant ADRs occurred more than a year after starting therapy, which underscores the importance of ongoing monitoring. 


\section{Chemotherapy-Induced Nausea and Vomiting in Children Receiving High Dose Methotrexate with or without Vincristine: Preliminary Results}

Jacqueline Flank ${ }^{\prime, 4}$, Sara Lavoratore ${ }^{l}$, Helen Vol', Tracey Taylor ${ }^{l}$, Elyse Zelunka', Paul Nathan'2, Anne Marie Maloney3, L Lee Dupuis, 'Department of Pharmacy, The Hospital for Sick Children, Toronto, ON 2Department of Paediatrics, Division of Haematology/Oncology, The Hospital for Sick Children, Toronto, ON

${ }^{3}$ Department of Nursing, The Hospital for Sick Children, Toronto, ON ${ }^{4}$ Leslie Dan Faculty of Pharmacy, University of Toronto, Toronto, ON

Rationale: Chemotherapy-induced nausea and vomiting (CINV) negatively influences the quality of life of children receiving chemotherapy. Little is known about the severity of CINV experienced by children receiving IV methotrexate $\geq 1 \mathrm{~g} / \mathrm{m}^{2} /$ dose (HD-MTX).

Objective: To describe the prevalence of acute and delayed phase CINV in children aged 4-18 years receiving HD-MTX \pm vincristine.

Study Design and Methods: Children about to receive HD-MTX were eligible to participate in this prospective, observational study. Patients received antiemetics as ordered by their primary care team. Nausea severity (assessed using the Pediatric Nausea Assessment Tool; PeNAT), time of emetic episodes, and administration of antiemetics were recorded in a diary beginning immediately prior to HD-MTX administration, for 24 hours after the patient achieved a MTX concentration of $<0.1 \mu \mathrm{M}$ (acute phase), and for up to an additional 7 days (delayed phase). Complete CINV control was defined as: no vomiting, no retching and a maximum PeNAT score of 1 (out of 4).

Results: Data are available for 23 patients (mean age: $12 \pm 3.9$ years; 14 boys). Fourteen patients received HD-MTX plus vincristine while 9 received HD-MTX alone. The average MTX dose was $9 \mathrm{~g} / \mathrm{m}^{2}$ (range: $\left.3-12 \mathrm{~g} / \mathrm{m}^{2}\right)$. Antiemetic prophylaxis consisted of either ondansetron (16) or granisetron (7) with (10) or without (13) dexamethasone. Six patients also received nabilone. Ten patients received breakthrough antiemetics (lorazepam \pm dimenhydrinate). Mean duration of the acute and delayed phases were 81.7 and 144.8 hours, respectively. One (4\%) and $7(30 \%)$ patients experienced complete CINV control during the acute and delayed phases, respectively. More patients experienced complete vomiting control during the acute $(52 \%)$ and delayed $(61 \%)$ phases than experienced complete nausea control (4 and 30\%, respectively).

Conclusion: Acute and delayed phase CINV control, most especially nausea control, following HD-MTX administration is sub-optimal. Subsequent analyses will evaluate the influence of guideline-consistent antiemetic prophylaxis on CINV control.

\section{Safe Swallowing of Oral Liquid Medications in Patients with Dysphagia: A Patient Quality and Safety Initiative}

\section{Aarthi Iyer, Darien Heathcote}

Trillium Health Partners - Mississanga Hospital, Mississanga, ON

Rationale: Patients with oropharyngeal dysphagia are at aspiration risk, making the administration of oral medications challenging. Liquid medications may be too thin and the use of xantham gum based thickeners for liquid medications has not been evaluated.

Objectives: This project sought to:

- classify the viscosity of commonly prescribed liquid medications

- standardize thickening of liquid medications

- establish an institution specific collaborative process for thickening liquid medications
Study Design and Methods: Viscosity of commonly prescribed liquid medications was visually determined. Next, serial quantities of water (thinnest consistency) were added to applesauce to determine the threshold at which its puree consistency is altered. Finally, medications prescribed in volumes above $10 \mathrm{mls}$ were tested with thickening agent. Viscosity of the prepared product was determined using The Line Spread Test.

Results: It was determined that up to $2.5 \mathrm{ml}$ of thin liquid added to $16 \mathrm{ml}$ of applesauce does not alter the consistency of applesauce. For medications prescribed in volumes greater than $10 \mathrm{mls}$, for which crushable alternatives are not available, recipes with thickener were established. The final consistency attained was pudding thickening (with the exception of Lactulose).

\begin{tabular}{|c|c|c|c|}
\hline \multirow[b]{2}{*}{ Medication } & \multicolumn{2}{|c|}{ Dose is More Than $10 \mathrm{ml}$ : } & \multirow[b]{2}{*}{ Special Instructions } \\
\hline & Usual Dose & $\begin{array}{l}\text { Amount of } \\
\text { thickener to } \\
\text { be added }\end{array}$ & \\
\hline$\overline{\mathrm{CAS}-\mathrm{MAG}}$ & $15 \mathrm{ml}$ & 1 packet & Stir \\
\hline Docusate Sodium & $25 \mathrm{ml}$ & 2 packets & $\begin{array}{l}\text { Stir \& let sit } \\
\text { for } 10 \text { mins. }\end{array}$ \\
\hline Hydroxyzine & $25 \mathrm{ml}$ & 2 packets & Stir \\
\hline Lactulose* $^{*}$ & $30 \mathrm{ml}$ & 4 packets & Stir (see * below) \\
\hline Lithium & $20 \mathrm{ml}$ & 2 packets & $\begin{array}{l}\text { Stir } \& \text { let sit } \\
\text { for } 30 \text { mins. }\end{array}$ \\
\hline Milk of Magnesia & $30 \mathrm{ml}$ & 1 packet & Stir \\
\hline Potassium chloride & $15 \mathrm{ml}$ & 1 packet & $\begin{array}{l}\text { Stir \& let sit } \\
\text { for } 10 \text { mins. }\end{array}$ \\
\hline Theophylline & $26.5 \mathrm{ml}$ & 1 packet & Stir \\
\hline
\end{tabular}

*Lactulose can only be thickened to honey thick. If the patient is on pudding thick do not give. Consult Pharmacy.

Conclusion: Administering liquid medications to patients with oropharyngeal dysphagia is a significant challenge. We developed a standardized approach to the safe and effective administration of liquid medications.

\section{Evaluation of a Secondary Stroke Prevention Checklist Implemented on a Stroke-Medicine Unit in a Community Teaching Hospital}

Monica Lee, Vickie Chang, Parisa Parnian, Rochelle Liem, Tiffany Kan North York General Hospital, Toronto, ON

Rationale: The use of antithrombotic therapies and management of cardiovascular risk factors are vital to preventing recurrent strokes. Hospital pharmacists can play an important role in ensuring patients admitted with a stroke or transient ischemic attack (TIA) be discharged on evidence-based secondary prevention medications.

Description and Steps Taken: Based on current evidence and best practice recommendations, a secondary stroke prevention checklist was developed and implemented on the stroke-medicine unit. The checklist assists pharmacists in the systematic assessment of patients' stroke risk factors as well as their secondary prevention therapies. It also serves as a communication tool for follow-up issues when patients are reassessed at the stroke prevention clinic. A retrospective chart review was conducted to evaluate the adherence to checklist completion by pharmacists. In addition, the proportion of patients discharged on secondary prevention drug therapies was examined.

Evaluation: During a 2-month period, 37 patients with a mean age of 73.4 years were discharged with a diagnosis of stroke or TIA. The secondary stroke prevention checklist was completed in 31 (84\%) patients, with follow-up issues documented in 29 (94\%) of them. 
Among the 35 (95\%) patients who suffered from an ischemic event, $33(94 \%)$ were discharged on antithrombotic therapies, $26(74 \%)$ on antihypertensive drugs, and $29(83 \%)$ on lipid-lowering agents. A higher proportion of these patients with a completed checklist were discharged on secondary prevention therapies than those without a checklist (antithrombotics, $100 \%$ vs. $67 \%$; antihypertensives, $79 \%$ vs. $50 \%$; lipid-lowering drugs, $93 \%$ vs. $33 \%$ ).

Importance: The implementation of a checklist by pharmacists helps ensure consistent evaluation of stroke survivor's risk factors and application of appropriate secondary prevention therapies. It may also improve follow-up management of stroke patients across the continuum of care. Such a tool may be adopted by other hospital units to ensure optimal care in stroke patients.

\section{Losartan-induced Autoimmune Hepatotoxicity: A Case Report}

Rochelle Liem, Monica Lee, Nitin Sarin

North York General Hospital

Rationale: Drug-induced autoimmune hepatitis (DIAIH) is wellcharacterized and makes up a significant portion of autoimmune hepatitis. The angiotensin receptor blockers (ARBs), have been linked to hepatotoxicity. We describe a probable case of losartan-induced autoimmune hepatotoxicity, which represents the first such case reported in the literature.

Description: A 74-year-old female presented to hospital with a 6-week history of malaise, low-grade fever, anorexia, weight loss and jaundice. Her past medical history consisted of hypertension, noninsulin-dependent diabetes mellitus, gastrointestinal reflux, osteoporosis, and depression. Medications at the time of admission included metformin, lansoprazole, escitalopram, aspirin, vitamin D, calcium carbonate, and losartan $100 \mathrm{mg}$ daily. Losartan was started 4 months prior to her initial symptoms. The patient denied alcohol or illicit drug use. Laboratory results showed ALT 560 U/L, AST 827 U/L, ALP 135 $\mathrm{U} / \mathrm{L}$, total bilirubin $359 \mathrm{umol} / \mathrm{L}$, GGT $396 \mathrm{U} / \mathrm{L}$, and INR 2.15. Viral serologies were negative. IgG was grossly elevated at $30.91 \mathrm{~g} / \mathrm{L}$ and ANA was positive at 1.6. A liver biopsy was consistent with autoimmune liver injury. Corticosteroids were started and the patient's liver enzymes gradually decreased. Losartan was never resumed. Her followup investigations 21 months later revealed normal liver enzymes. She has a complete resolution of clinical symptoms.

Causality Assessment: Drug molecules can trigger an immune response when they are bound to self-proteins. The patient demonstrated clinical characteristics of autoimmune hepatitis, which resolved after losartan was discontinued. The Naranjo score of 7 indicates a probable adverse drug reaction.

Literature Evaluation: Hepatotoxicity associated with ARB's has been reported in the literature. There has been one case report describing probable autoimmune hepatitis with irbesartan.

Importance: Practitioners should be aware of this potentially fatal adverse drug reaction with losartan and other ARBs. In patients who present with autoimmune hepatotoxicity, a thorough medication review should be performed to rule out this adverse drug reaction.

\section{Venous Thromboembolism Prophylaxis in Long Term Care: A Prevalence Chart Review}

Tiffany Kan ${ }^{1}$, Danette Beechinor ${ }^{2}$, Anjana Sengar ${ }^{3}$, Ramola Bhojwani', Christina Lee', Barbara Clive', Allan Mills',3

${ }^{\prime}$ Leslie Dan Faculty of Pharmacy, University of Toronto, Toronto, ON
${ }^{2}$ Trillium Health Partners Credit Valley Hospital, Mississanga, ON

${ }^{3}$ Trillium Health Partners Mississanga Hospital, Mississanga, ON

Rationale: Despite recommendations to provide venous thromboembolism (VTE) prophylaxis in acutely ill medical and surgical patients, there are currently no recommendations that suggest the use of thromboprophylaxis in long term care (LTC) patients. There is also a lack of evidence demonstrating the safety and efficacy of thromboprophylaxis in this population.

Objectives: To assess current practices of thromboprophylaxis and to determine if there is an excess of patients receiving thromboprophylaxis in the LTC setting.

Study Design and Methods: A retrospective chart review was conducted at a large community teaching hospital. Patients admitted to complex continuing care, alternate level of care, or LTC beds were eligible for inclusion during a two-week evaluation period. The Padua Prediction Score was used to assess risk factors for VTE, and to stratify patients into high or low risk of VTE. The rate of pharmacologic thromboprophylaxis and the cost of providing thromboprophylaxis to low risk patients were determined.

Results: A total of 124 patients with a mean age of 76.3 years were included in the study. Advanced age, acute infection, and reduced mobility were the most prevalent risk factors for VTE. Seventy-three (59\%) patients were receiving thromboprophylaxis. Among these patients receiving thromboprophylaxis, 55 (75\%) patients were considered to be at low risk of VTE. The annual cost of providing thromboprophylaxis to low risk patients was approximately $\$ 165,600$.

Conclusion: These findings suggest that there may be an excess of LTC patients receiving thromboprophylaxis despite being at low risk of VTE. This prompts the need for education and validated risk assessment models to better identify LTC patients who may benefit from thromboprophylaxis. This would help minimize exposure in low risk patients and potentially provide cost-savings.

\section{Patterns and Predictors of Use of Oral Anticoagulants for Atrial Fibrillation}

Caroline Brais, ${ }^{1,2}$, Marie-Hélène Turgeon ${ }^{1,2}$, Josiane Larochelle ${ }^{1,2}$, Lucie Blais, ${ }^{2,3}$, Marie-Pierre Garant, Anne-Sophie Tousignant, Diane Rochon 5 , Paul Farand ${ }^{5}$, Geneviève Letemplier ${ }^{5}$, Sylvie Perreault ${ }^{2}$, Marie-France Beauchesne $e^{1,2,4}$

${ }^{I}$ Pharmacy Services, Centre hospitalier universitaire de Sherbrooke, Sherbrooke, QC

${ }^{2}$ Faculty of Pharmacy, Université de Montréal, Montréal, QC

${ }^{3}$ Research Center, Hôpital du Sacré-Coeur de Montréal, Montréal, QC

${ }^{4}$ Centre de recherche Clinique Étienne-Le Bel, Centre hospitalier universitaire de Sherbrooke, Sherbrooke, QC

${ }^{5}$ Department of Medicine, Centre hospitalier universitaire de Sherbrooke, Université de Sherbrooke, Sherbrooke, QC

Rationale: In the era of new oral anticoagulants (NOAC) for atrial fibrillation (AF), few studies have identified patterns of NOAC use over warfarin.

Objectives: To describe oral anticoagulants (OAC) use and to identify patterns associated with the choice of NOAC over warfarin.

Methods: A cohort of patients on OAC for AF was built from inpatient records of hospitalisations between October 2011 and March 2013. A nested case-control study was conducted to identify predictors of NOAC use among new users of OAC.

Results: In the 6-month period following dabigatran availability in the hospital, 447 patients met our inclusion criteria: 59 (13\%) were on NOAC (dabigatran) and $388(87 \%)$ on warfarin. About 71\%, 25\% 
and $3 \%$ of patients on NOAC were prevalent users, incident users, and patients who switched OAC, respectively. The NOAC group had a lower mean $\mathrm{CHADS}_{2}$ score (2.34 versus $2.76, p=0.018$ ), a higher mean creatinine clearance ( 72 versus $53 \mathrm{~mL} / \mathrm{min}, p<0.001$ ), a lower proportion of coronary artery disease (34\% versus $55 \%, p=0.002)$ and a lower proportion of dementia ( $9 \%$ versus $20 \%, p=0.039)$ than the warfarin group.

In the nested case-control study ( $n=245$ incident users), 40 (16\%) patients on NOAC (dabigatran and rivaroxaban) were compared to $205(84 \%)$ patients on warfarin, using a multiple logistic regression analysis. Renal insufficiency independently decreased the probability of NOAC use versus no renal insufficiency (OR 0.363; 95\% confidence interval $0.133-0.990)$. NOAC use probability independently decreased whilst the number of chronic medications increased (OR 0.844; 95\% confidence interval 0.748 - 0.952). Prior stroke independently predicted NOAC use compared to no stroke history (OR 2.480; 95\% confidence interval 1.108 - 5.549).

Conclusion: The percentage of NOAC use is low. Patients with a normal renal function, a stroke history and fewer chronic medications are more likely to receive a new oral anticoagulant.

\section{Aluminum Exposure from Calcium Gluconate $10 \%$ Injection in Neonates Receiving Parenteral Nutrition}

Renee Woo ${ }^{I}$, Amelia Rodrigues', Vera Riss ${ }^{1}$, Marialena Mouzaki', Joan Brennan-Donnan ${ }^{3}$, Glenda Courtney-Martin ${ }^{3}$,Elaine Lau ${ }^{I}$ ${ }^{\prime}$ Department of Pharmacy, The Hospital for Sick Children, Toronto, ON 'Department of Gastroenterology, Hepatology and Nutrition, The Hospital for Sick Children, Toronto, ON

${ }^{3}$ Department of Clinical Dietetics, The Hospital for Sick Children, Toronto, ON

Rationale: Aluminum exposure from parenteral nutrition (PN) exceeding $4-5 \mathrm{mcg} / \mathrm{kg} /$ day can be associated with central nervous system toxicity, bone and liver damage, and anemia in preterm infants and those receiving prolonged PN. In 2011, Health Canada issued an alert regarding aluminum leaching from glass vials of calcium gluconate $10 \%$ injection manufactured by Pharmaceutical Partners of Canada (PPC), the sole Canadian supplier. SickKids ${ }^{\circledR}$ uses this product to prepare PN.

Description of Concept: To identify alternative calcium gluconate $10 \%$ injectable products that can be safety added to PN. To predict aluminum exposure in Neonatal Intensive Care Unit (NICU) patients receiving PN containing calcium gluconate from PPC and compare to predicted aluminum exposure from alternative products.

Problem Resolution: Alternative calcium gluconate products were investigated by the SickKids $®$ Drug Information Service. The predicted amount of aluminum neonates received from PPC calcium gluconate in PN during July 2011 was calculated, and compared to predicted amounts from alternative sources. Actual aluminum content in SickKids ${ }^{\circledR}$ PN (with PPC product) was measured using inductively coupled plasma mass spectrometry.

Evaluation: Calcium gluconate $10 \%$ injections by B. Braun $(10 \mathrm{~mL}$ plastic ampoule, Germany) and Phebra (10mL glass vial, Australia) were identified. The predicted average aluminum content neonates would receive from calcium gluconate products in PN by PPC, B. Braun, and Phebra was $62 \mathrm{mcg} / \mathrm{kg} /$ day, $1.25 \mathrm{mcg} / \mathrm{kg} / \mathrm{day}$, and 24 $\mathrm{mcg} / \mathrm{kg} /$ day, respectively. The predicted aluminum content from PPC and Phebra products exceeded the recommended safe aluminum limit, unlike the B. Braun product. Measured aluminum content in our PN samples (with PPC product) was $29.2 \mathrm{mcg} / \mathrm{kg} /$ day, six times the rec- ommended safe limit. International pediatric advisory groups have recommended using calcium gluconate packaged in plastic to avoid aluminum leaching.

Importance to Practice: SickKids® pharmacy has switched to using calcium gluconate manufactured by B. Braun and is following PPC's investigation for alternate packaging of calcium gluconate.

\section{Comparison of the Level of Conformity between the Medication Management Standards of Accreditation Canada and the Results of the Hospital Pharmacy in Canada Report}

Isabelle Barthélémy ${ }^{l}$, Denis Lebel', Cynthia Tanguay ${ }^{l}$, Régis Vaillancourt ${ }^{2}$ Chris Niro ${ }^{3}$, Jean-François Bussières ${ }^{I, 4}$

'Pharmacy Department and Pharmacy Practice Research Unit, Centre hospitalier universitaire Sainte-Justine, Montréal, QC

'Pharmacy Department, Children's Hospital of Eastern Ontario,

Ottawa, ON

${ }^{3}$ Accreditation Canada, Ottawa, ON

${ }^{4}$ Faculty of Pharmacy, Université de Montréal, Montréal, QC

Rationale: We proposed to Accreditation Canada to explore the discrepancy about the conformity of the drug use process between the accreditation process compliance rating and the Canadian pharmacy survey.

Objectives: The main objective was to compare the level of conformity between the Medication Management Standards (MMS) of Accreditation Canada and the results of the Hospital Pharmacy in Canada (HPC) Report. The secondary objective was to discuss any important discrepancies between both sources.

Study design and methods: This is a retrospective cross-sectional study. Whenever possible, each MMS criterion was paired by a pharmacy resident with specific results from the 2009-2010 HPC report. Pairing was validated by a five-person panel. A discrepancy ratio was calculated between the results of the 2009-2010 HPC and the 2010 MMS by dividing both levels of conformity per criterion.

Results: A total of $60 \%$ (81/135 criteria) of the MMS criteria have been paired with some 2009-2010 HPC results by the panel members. The average calculated discrepancy ratio between MMS and HPC results is $0.62 \pm 0.28$ [min: 0.05 - max: 1.19]. The average discrepancy ratio between MMS and HPC results per domain was respectively the following: 0.49 (safely administering medications), 0.58 (accurately preparing and dispensing medications), 0.61 (working together to promote medication safety), 0.62 (carefully selecting and procuring medications), 0.64 (monitoring quality and achieving positive results), 0.71 (appropriately ordering and transcribing medications) and 0.76 (properly labelling and storing medications). We noted an important discrepancy between the 2010 MMS on-site surveys and 2009/2010 HPC results for a total of 62 criteria.

Conclusion: A total of $60 \%$ of the MMS criteria have been paired with some 2009-2010 HPC results. The average calculated discrepancy ratio between both sources is $0.62 \pm 0.28$. Further studies are required to explore the reasons for such discrepancy.

\section{The Role of Clinical Informatics in Improving the Assessment of Venous Thromboembolism Risk and Prophylaxis}

Vaishali Sengar, Brenda Cardiff, Vera Dounaevskaia, Heather Kertland, Karen Ng, Rosemary Tanzini, Chris Hayes

St Michael's Hospital, Toronto, ON 
Rationale: Due to the morbidity and mortality associated with hospital acquired venous thromboembolism (VTE), Accreditation Canada has made the documentation of VTE risk assessment a required organizational practice. We wanted to determine how a recently implemented Computerized Provider Order Entry (CPOE) system could support this requirement.

Description of Concept: A hospital specific VTE prophylaxis guideline had informed the development of a paper-based physician's order set which included risk assessment documentation. This order set was used to build the service specific admission order sets during CPOE implementation. Following implementation of CPOE, data from the physician ordering system was extracted to identify the percentage of patients with documented VTE prophylaxis assessment and/or treatment within 24 hours of admission. Data was compiled quarterly on a corporate and admitting service basis and shared unblinded with physician and care team leadership.

Methods and Evaluation: Initial assessment/treatment rates were established. Following the initial roll-out, optimizing strategies were implemented using Plan Do Study Act methodology to assess for impact on the overall and individual service rates. Changes implemented included; incorporating the VTE order set into the admission order sets that had been missed on initial build, opening the VTE order set section within the admission order set to prompt for assessment, modifying order set content to address surgical services pre-operative considerations and adding an electronic reminder when patients were admitted not using an admission order set. Each of these contributed to increasing rates of VTE prophylaxis assessment/ treatment.

Conclusions: The use of clinical informatics order set standardization and design principles and the sharing of service level data was successful in improving the rates of VTE prophylaxis assessment/treatment.

\section{How Do Local, Provincial and National Perspectives on Clinical Pharmacy Key Performance Indicator Critical Activity Areas Compare?}

H Bannerman', S Gorman ${ }^{2}, K$ Toombs $^{3}$, J Lo ${ }^{l}$, S Shukla ${ }^{l}$, D Doucette, R Slavik', B Semchuk', W Chan', N Benninger', NMacKinnon ${ }^{6}$,

C Bell, J Slobodan ${ }^{8}$ C Lyder ${ }^{2}$, T Pereira ${ }^{8}$, A Bjelajac-Mejia ${ }^{10}$, S Spina ${ }^{11}$, $O$ Fernandes ${ }^{1,2}$

${ }^{1}$ Leslie Dan Faculty of Pharmacy, University of Toronto, Toronto, ON

${ }^{2}$ Interior Health Authority, Kelowna, BC

${ }^{3}$ Capital Health, Halifax, NS

${ }^{4}$ Horizon Health Network, Moncton, NB

${ }^{5}$ Regina Qu'Appelle Health Region, Regina, SK

${ }^{6}$ University of Cincinnati, Cincinnati, $\mathrm{OH}$

${ }^{7}$ Mount Sinai Hospital, Toronto, $O N$

${ }^{8}$ Alberta Health Services, Red Deer, AB

${ }^{9}$ Canadian Society of Hospital Pharmacists, Edmonton, AB/Ottawa, ON

${ }^{10}$ The Hospital for Sick Children, Toronto, ON

${ }^{11}$ Vancouver Island Health Authority, Victoria, BC

${ }^{12}$ University Health Network, Toronto, ON

Rationale: A set of hospital clinical pharmacy key performance indicators (cpKPI) was recently developed using a systematic, national, consensus-building process. The cpKPI were grouped into 8 evidenceinformed critical activity areas (i.e. pharmaceutical care, discharge medication reconciliation, patient medication education) representing hospital pharmacist best practices which demonstrated improvements in meaningful patient outcomes. The relative importance of the critical activities is not known.
Description: Our objective was to determine local, provincial, and national perspectives of pharmacists on the relative importance of cpKPI critical activities and how these perspectives compare with each other. Participant pharmacist subgroups included the: national cpKPI working group ( $\mathrm{n}=11)$, national Delphi panel $(\mathrm{n}=25)$, provincial subgroup (Ontario branch) ( $\mathrm{n}=14)$, local clinical pharmacy leaders $(\mathrm{n}=10)$, and local front line pharmacists (Kelowna/ Toronto $\mathrm{n}=23$ ). Each participant was asked to identify the relative importance of 8 critical activities based on the question, "Will a cpKPI in this critical activity area advance clinical pharmacy practice to improve the quality of patient care?" Each participant was given 20 "dot" votes to assess (assign dots for relative importance) the critical activities.

Evaluation: A total of 83 hospital pharmacists from all 10 provinces participated. Pooled results indicated that the three most important critical activity areas were; (1) Pharmaceutical Care - Integrated (24\%); (2) Interprofessional Patient Care Rounds (15\%); and (3) Discharge Medication Reconciliation (13\%). Between subgroups, the most important critical activity was the same (Pharmaceutical Care), but there was some variation on second and third rankings. The national Delphi panel ranked Interprofessional Patient Care Rounds and Admission Medication Reconciliation second and third most important respectively.

Importance: Pharmacists' perspectives at the local, provincial, and national levels appear to align on the most important cpKPI critical activities. Pan-Canadian collaboration to standardly implement cpKPI in these domains may serve to advance pharmacy practice to improve patient outcomes.

\section{The Role of Online/Smartphone Applications in Type II Diabetes Management: A Qualitative Study}

Alina R Rashid, Certina Ho

School of Pharmacy, University of Waterloo, Waterloo, ON

Rationale: Diabetes is a chronic medical condition that affects the lives of over 9 million Canadians. Multiple interventions, including smartphone applications (or apps), have been developed for patients to self-manage this condition.

Description of Concept: This study intends to identify a list of smartphone applications that can be recommended to patients for selfmanagement of diabetes with respect to medication adherence, physical activity, diet, and weight management.

Steps Taken: An environmental scan was performed to identify and evaluate the top 7 diabetes management apps for iPhone, iPad, iPod Touch, Android, and Windows Phones. These apps were assessed based on features, usability, and their authority, accuracy, currency, objectivity, and quality. We interviewed 4 Certified Diabetes Educators (CDEs) and obtained their feedback and experience on the use of these apps in diabetes patient education.

Evaluation: The assessment of the 7 apps revealed some key features that were available in some but not others - medication reminders; tracking of blood glucose readings, insulin dosing, physical activity, weight, blood pressure readings, and carbohydrate intake; electronic synchronization with healthcare providers, and glucometer compatibility. We identified that simplicity of the app, ease of use, and cost were the key factors in determining the best app for self-management of diabetes. iBG Star and Glucose Buddy both fulfilled these criteria, and Tactio Health was a close second.

Importance to Practice: Smartphones are now an integral part of the daily life of many Canadians. As a result, there is an increase in apps available for self-management of diabetes. Patients play a critical role 
in chronic disease management. Pharmacists can expect to receive questions about the role of smartphone apps in the management of diabetes. When recommending phone apps to diabetic patients, it is important to individualize app selection to ensure optimal benefits to patient care.

\section{Laboratory Test Ordering by Pharmacists in Canada: A Nationwide Study of Policies and Practices}

\section{Peter Loewen, Julia Higgins}

Faculty of Pharmaceutical Sciences, The University of British Columbia, Vancouver, BC

Rationale: Clinical laboratory tests provide information that is essential for pharmacotherapeutic decision-making. Having the authority to order tests also streamlines care provision. There is limited data available on the prevalence and nature of policies and regulation to support laboratory test ordering by pharmacists.

Objective: To characterize pharmacist laboratory test ordering policies across Canadian health delivery units (HDU: health authorities, regions, hospitals).

Study Design and Methods: Pan-Canadian cross-sectional policy analysis including legislative, regulatory, professional association, HDU, and individual pharmacist key informant perspectives. Data sources were web searches and key informants (pharmacy directors and practice leaders) in all Canadian HDUs. Key informants were approached by e-mail to request relevant policy documentation. Policies were stratified geographically and categorized by scope, nature, and context using an iterative approach.

Results: Six provinces have legislation permitting pharmacists to order lab tests and in 2 of these the pharmacy regulator has implemented policies accordingly (QC, $\mathrm{AB}) .108$ key informants responded, representing $90 \%$ of identified HDUs. Of the 53 policies identified, 11 authorize pharmacists to order a broad scope of laboratory tests, 18 restrict pharmacists to a limited set of tests or restrict this authority to specific settings. Policy development is underway in 9 of the 24 HDUs where none currently exists. In $4 \mathrm{HDUs}$ an existing policy is being expanded in scope. Broadly permissive policies were found in provinces where legislation is permissive or pending with the exception of British Columbia where $50 \%$ of HDUs have broadly permissive policies despite the lack of supportive legislation. Besides a lack of regulatory support, the major barriers identified by key informants were laboratory accreditation standards and sources of funding for laboratory tests.

Conclusions: Laboratory test ordering by Canadian HDU pharmacists is common and moving toward ubiquity along with legislation and regulatory changes.

\section{National Canadian Venous Thromboembolism (VTE) Prevention Audit Day: Design and Results}

Artemis Diamantouros ${ }^{1,2,3}$, Anne MacLaurin ${ }^{4}$, Virginia Flintoft ${ }^{2,3}$, William Geerts ${ }^{1,2,3}$

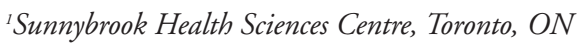

${ }^{2}$ Safer Healthcare Now

${ }^{3}$ University of Toronto, Toronto, ON

${ }^{4}$ Canadian Patient Safety Institute, Edmonton, $A B$

Rationale: Venous Thromboembolism (VTE) is one of the most common, and costly complications of hospitalization. Most hospitalized patients are at risk for VTE and studies prove VTE is preventable.
Objectives: To establish a national estimate of VTE prophylaxis rates, raise awareness, and promote use of a new VTE data collection tool created for the audit.

Methods: A National Call to Action and information call was held to promote participation. National and provincial agencies were involved to endorse the audit and hospitals and health authorities were invited to register. The audit was to be conducted on a sample of at least 20 general medicine or surgery patients or both. A detailed workbook providing instructions on how to participate and an optical mark recognition data collection form was made available to all participants. Data were submitted by fax or direct entry to the CPSI Patient Safety Metrics System.

Results: The Audit Day was a success in attracting interest and establishing a Canadian VTE prophylaxis estimate. Data on 4667 patients was reported by 118 hospitals, up from 14 in 2012 . . Overall $81 \%$ of patients received appropriate VTE prophylaxis. The use of order sets contributed to higher VTE prophylaxis rates. Results showed variability in VTE prophylaxis by patient group, province and provincial regions. Audit Day survey feedback indicated all respondents would participate in a 2014 Audit Day.

Conclusions: Providing detailed instructions, an audit tool and audit support reduced reporting burden and improved participation. Limiting the patient sample to medical/surgical patients made it difficult for small sites to achieve the desired sample size. Participant education was required to assist with determinations of 'appropriate VTE prophylaxis' and reasons prophylaxis was not used. Improved planning and participation strategies will be required to expand the audit to even more centers in 2014.

\section{Improving Influenza Vaccination Uptake in the Progressive Care Unit of a Community Teaching Hospital}

Sonia Wang, Sumit Raybardhan

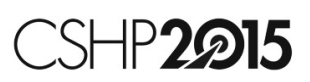

North York General Hospital, Toronto, ON

Rationale: The development of a coordinated influenza vaccination program among a vulnerable institutional population is important to reduce the risk of influenza infection and complications.

Description: The Rehabilitation and Progressive Care Unit (RPCU) at North York General Hospital is a short stay unit for patients awaiting placement to alternate level of care facilities. The patients on this unit have an average age of eighty-five years with multiple comorbidities, representing a high risk group for influenza infection and complications. Recurrent influenza outbreaks have been noted particularly in this unit. A pharmacist-led initiative of systematically screening and educating patients was developed to facilitate a collaborative approach for influenza vaccination in this vulnerable population.

Method: An evidence-based screening tool with expert input was created to determine eligibility for the influenza vaccine. An in-service was given to RPCU staff, educating them on the safety and effectiveness of the influenza vaccine and familiarizing them with the screening tool workflow. Collaboratively, patient's consent was obtained. The clinical pharmacist ensured all patients who consented, received the vaccine prior to discharge from the unit. A standardized letter indicating vaccine administration date was included upon discharge. 


\section{PPC 2014 POSTER ABSTRACTS / RÉSUMÉS DES AFFICHES DE LA CPP 2014}

Evaluations: During a three and a half month period, ninety patients out of the one hundred and twenty-five admitted to RPCU were screened. Of the ninety patients, fifty-four were eligible for influenza vaccinations. A total of forty-four patients consented and received the vaccine. This initiative resulted in a more than five time increase in ordered and administered influenza vaccine compared to the same prior period on the unit.

Impact: The implementation of an interprofessional vaccination program led to increased influenza vaccine uptake among a vulnerable population. Implementing the pharmacist driven influenza screening tool in the whole hospital along with screening for other vaccines will be the next goal for our institution.

\section{Appropriateness of Using Alternate Oral Anticoagulants in Poorly Controlled Warfarin Patients}

\section{CSHP2Ф15}

Debbie Kwan, Patricia Marr, Kori Leblanc, Chandani Upadhyay, Manal Rostom, Jessica Jakob, Victoria Siu, Toni Basinski University Health Network and University of Toronto, Toronto, ON

Rationale: Patient outcomes with warfarin therapy are best when INR time in therapeutic range (TTR) is optimized. A TTR of $\geq 60 \%$ has been suggested for achieving high quality anticoagulation. At the Toronto Western Family Health Team, warfarin continues to be the most commonly used oral anticoagulant and is managed by the pharmacists.

Description: We conducted a quality improvement evaluation to 1) Assess the quality of warfarin therapy management using TTR, 2) Compare the characteristics of patients who achieved an accepted TTR vs. those who did not, 3) Assess the appropriateness of switching patients with poor TTRs to a novel oral anticoagulant (NOAC).

Steps Taken to Identify and Resolve Problem: A retrospective chart review was conducted for patients on warfarin therapy for a 12 month period. TTR was calculated using the Rosendaal method. Demographic and clinical characteristics were compared between patients with poor (i.e. TTR $<60 \%$ ) vs. good (i.e.TTR $\geq 60 \%$ ) control. Charts of poorly controlled patients were further reviewed to determine whether they could have been safely switched to a NOAC. Specific criteria used included: appropriate indication for anticoagulation, patient comorbidities, renal function and potential for drug interactions.

Evaluation: A total of 168 charts were reviewed; 30\% (51) had an average TTR $<60 \%$. There were no statistically significant differences in demographic and clinical characteristics between poor vs. acceptable control groups. Of the poor control group, 65\% (33) had an indication that allowed use of a NOAC. Five $(9.8 \%)$ patients had an absolute contraindication to using a NOAC. Relative contraindications and precautions were not assessed since appropriateness of NOAC therapy would depend on subsequent interventions to manage these.

Implications for Future Practice: TTRs should be routinely assessed proactively to identify poorly controlled warfarin patients. Those with suboptimal TTRs should be considered for NOAC therapy unless a contraindication exists.

\section{Personalized Medicine: Teaching Strategies for a Novel Clinical Pharmacy Residency Rotation}

\section{NM Faccal ${ }^{l}$ S Jansen ${ }^{l}, R$ B Kim ${ }^{l, 2}$}

${ }^{1}$ London Health Sciences Centre, London, ON

${ }^{2}$ Schulich School of Medicine and Dentistry, Western University, London, $O N$

Rationale: Pharmacists are well positioned within the health care team to provide patient care based on pharmacogenomics, an emerging field of clinical relevance for individualized drug therapy. Current curricula of the pharmacy schools and residency programs across Canada lack substantial education in this field.

Description: The ultimate goal of the rotation is to familiarize the resident with the new field of medicine known as personalized medicine or pharmacogenomics.

Implementation: To better develop the skills of pharmacists to be able to provide pharmacogenomics-based pharmaceutical care, a mandatory pharmacy residency rotation in personalized medicine was established. Learning objectives for the rotation were defined and specific, validated teaching strategies were deployed by the preceptor.

Evaluation: The residents were given a survey at the end of the rotation to assess the mandatory personalized medicine rotation and assess the teaching strategies used during the rotation (response rate of $80 \%)$. Answers to the survey questions used the following assessment scale: does not apply, strongly disagree, disagree, agree, and strongly agree

Relevance: Personalized medicine is a new and exciting field of medicine. To be able to use pharmacogenomics information to provide personalized therapeutic recommendations to patients, pharmacists need adequate training and education. The introduction of a mandatory pharmacy residency rotation achieves this learning need for future pharmacists. Teaching strategies that can be used by a pharmacist preceptor for a pharmacy residency rotation in personalized medicine have been described.

For the table that goes with this abstract, please see Abstract Appendix, available online at www.cjhp-online.ca/index.php/cjhp/issue/view/ $100 /$ show Toc

\section{Stroke Prediction in Atrial Fibrillation: Meta- analysis of the Predictive Performance of the $\mathrm{CHADS}_{2}$ and $\mathrm{CHA}_{2} \mathrm{DS}_{2}$-VASc Clinical Prediction Rules}

Peter Loewen, Christopher Yearwood

Faculty of Pharmaceutical Sciences, The University of British Columbia, Vancouver, $B C$

Rationale: Guidelines recommend using the $\mathrm{CHADS}_{2}$ or $\mathrm{CHADS}_{2}$ VASc stroke clinical prediction rules (CPRs) in patients with atrial fibrillation (AF). Their clinical usefulness is dependent on their predictive performance, which can be measured using stratumspecific likelihood ratios (SSLR). SSLR magnitudes indicate weak, moderate, or strong predictive performance. No prior research has studied the $\mathrm{CHADS}_{2}$ or $\mathrm{CHA}_{2} \mathrm{DS}_{2}$-VASc CPRs from this perspective.

Objectives: To measure the clinical usefulness of the $\mathrm{CHADS}_{2}$ and CHA DS -VASc CPRs for stroke prediction using SSLRs.

Study Design and Methods: Meta-analysis using PRISMA guidelines. Prospective and retrospective studies reporting stroke rates in $\mathrm{CHADS}_{2} / \mathrm{CHA}_{2} \mathrm{DS}_{2}-\mathrm{VAS} \mathrm{C}$ strata were included. Data was pooled with and without adjustment to account for the effects of antithrom- 
botic therapy use in cohorts where this was reported. SSLRs were computed using Peirce \& Cornell's method and predictive strength of the SSLRs were classified using Jaeschke's scheme.

Results: 2249 citations were screened and 43 articles were included in the analysis. Pooled adjusted $\mathrm{CHADS}_{2}$ data $(\mathrm{n}=30$ studies, $\mathrm{N}=319,992$ patients) showed that a score of 0 weakly predicts low stroke risk (SSLR- 0.225 ; 95\% CI 0.219 to 0.232 ) while a score $\geq 3$ weakly predicts increased stroke risk (SSLR+ 3.70; 95\% CI 3.66 to 3.75). Pooled adjusted $\mathrm{CHA}_{2} \mathrm{DS}_{2}$-VASc data $(\mathrm{n}=16$ studies, $\mathrm{N}=256,672$ patients) showed that a score of 0 predicts decreased stroke risk with moderate strength (SSLR- 0.104; 95\% CI 0.096 to 0.112 ) while a score $\geq 5$ weakly predicts increased stroke risk (SSLR+ 2.80; $95 \%$ CI 2.76 to 2.84). CHADS and CHA DS - VASc scores $\geq 3$ and $\geq 5$, respectively do not have sufficiently distinct SSLRs to warrant use of individual scores for clinical decision-making.

Conclusions: A CHA DS - VASc score of 0 is a clinically useful negative predictor of stroke. No other stratum or group of strata for $\mathrm{CHADS}_{2}$ or $\mathrm{CHA}_{2} \mathrm{DS}_{2}-\mathrm{VASc}$, including extreme scores, demonstrated better than weak stroke predictive performance in this comprehensive meta-analysis.

\section{Development of Guidelines for Safe Management of Antithrombotic Medications Prior to Elective Surgical and Diagnostic Procedures in a Community Hospital Setting}

\section{Shelita Dattani}

\section{CSHP2D15}

Queensway Carleton Hospital, Ottawa, ON

Rationale: Annually, $10 \%$ of patients taking antithrombotic agents undergo procedures that require temporary discontinuation of therapy. The ultimate goal is to minimize thromboembolic events while balancing risk of bleeding in the peri-procedural period. In recent years, we have seen increased use of new oral anticoagulants and anti platelets at our institution. Review of multiple patient cases has demonstrated inconsistencies in peri-procedural management of these agents.

Description: Our multidisciplinary task group developed a guideline, initially focusing on an approach to interruption of therapy for all commonly used antithrombotic agents. The primary goal was to facilitate decision making and to support safe and consistent practice. A secondary goal was to promote clear communication between all stakeholders regarding interruption of therapy prior to surgical or diagnostic procedures.

Steps Taken To Develop the Guideline: Due to the paucity of published evidence in this area, feedback was solicited from several external and internal stakeholders and a conservative, consensus based approach was used to develop recommendations.

Evaluation: The guideline was presented to key stakeholder groups including surgery, anesthesia, medicine, radiology, nursing and pharmacy. Stakeholder representatives then tested "real world" application of the guidelines to patients in our preoperative assessment clinic. Based on this initial evaluation, further suggestions were implemented. The evaluation validated that development of guidelines facilitated safe and consistent practice and education of patients prior to procedures. It also highlighted the importance of clear communication among all providers, the proceduralist and the patient.
Relevance to Current and Future Practice: This initiative provides a starting point to enable our providers to safely and consistently manage interruption of antithrombotic therapy prior to procedures. Another evaluation is ongoing, using a question-based audit tool to assess compliance with the guidelines in the preoperative setting followed by a patient interview on the day of surgery.

\section{Opportunities to Enhance Institutional Experiential Education in British Columbia: Learner Perspectives}

Michael Legal, Donna Rahmatian, Kyle Collins, Marguerite Billingsley, France Carriere, Patricia Gerber, Angela Kim-Sing, Peter J Zed,

Peter S Loewen

Faculty of Pharmaceutical Sciences, The University of British Columbia, Vancouver, $B C$

Background: It is a challenge to provide sufficient quantities of high quality institutional experiential placements for learners. In recent years, this issue has become increasingly acute in pharmacy due to curricular and program changes in Canada. In British Columbia a comprehensive multi-stakeholder engagement project was undertaken to identify solutions. This report describes the learner engagement portion of the project.

Objectives: To characterize the perspectives of pharmacy learners in relation to experiential education in the institutional environment.

Research Methods: The perspectives of undergraduate students, pharmacy practice residents and post graduate doctor of pharmacy students were gathered through focus groups and one on one structured interviews. Focus groups and interviews were recorded and the resulting transcripts were analyzed using qualitative methods and iterative coding to identify major themes.

Results: A total of 50 learners participated. Learners felt that the undergraduate program emphasizes community practice and that there is a lack of exposure to hospital practice. Undergraduate students reported being anxious prior to their hospital placements and spent much of their time on rotation learning to adapt to the practice environment. They felt that an early hospital experiential placement towards the end of second year would be beneficial. They also suggested updating course and practice lab content to include: hospital terminology, abbreviations, interpretation of labs, systematic approach and chart note writing. Learners viewed precepting as added work for pharmacists and expressed a desire for preceptors to be afforded more time "just to teach". Precepting models which incorporate peer, tiered or group learning were viewed positively. Learners expressed frustration at a mismatch in expectations between preceptors, learners, and the Experiential Office.

Conclusions: This project highlighted some key challenges faced by learners and suggests some possible solutions. These solutions will need to be part of a comprehensive institutional experiential education strategy.

\section{Exploring Innovative Institutional Learner- Preceptor Models across Health Disciplines: A Systematic Review}

Allison Gamble, Kieran Shah, Stacey Tkachuk, Michael Legal, Peter S Loewen, Peter J Zed

Faculty of Pharmaceutical Sciences, The University of British Columbia, Vancouver, $B C$ 
Background: It is a challenge to provide sufficient quantities of high quality experiential placements for learners in hospital settings. In recent years, this issue has become increasingly acute due to curricular and program changes in Canada. Most placements in institutional pharmacy employ the traditional 1:1 (learner-to-preceptor model). Drawbacks of this model are an inability to adapt to increasing numbers of learners in the system and lack of opportunities for peerlearning. Novel (>1:1) models may offer a solution.

Objectives: To conduct a systematic review of the literature encompassing multiple health disciplines' experience with novel learner-preceptor models and to compare the advantages and disadvantages of these models. This systematic review will be valuable both to Canadian pharmacy programs, and to other health discipline faculties facing institutional experiential placement shortages.

Methods: Eight health and education literature databases were searched. Search terms related to the type of learner, health discipline (pharmacy, medicine, nursing, occupational therapy (OT), physiotherapy (PT), dietetics, dentistry, speech therapy or audiology), institutional/hospital experience, and preceptor model. Data from included studies were synthesised descriptively, and the advantages/disadvantages of different models of were summarized in a narrative format.

Results: Seventy-three articles were included in the final review. Sixty-four articles related to nursing, OT or PT education, while 4 articles related to pharmacy, 2 to dietetics, 2 to speech therapy while 1 was interprofessional. Eight learner-preceptor models were identified: $1: 1,2: 1,3: 1$, greater than $3: 1$ (up to 10:1), 2+:2+ (collaborative learning groups), 1:2 (shared precepting), 1:'0' (interprofessional precepting), and tiered (or 'learner-as-preceptor').

Conclusion: Each model offers unique advantages and disadvantages. While no model was superior to the others, the 2:1 model may facilitate peer learning and increase institutional placement capacity, without substantially increasing preceptor workload. To our knowledge this is the first review of its kind to include pharmacy models.

\section{Patient Medication Education at Discharge: A Multidisciplinary Team Based Approach (TEACH) CSHP2D15}

Cheyanne Boehm, Lynette Kosar, Lisa Ruda, Lori Zulyniak Regina Qu'Appelle Health Region, Regina, SK

Rationale: Healthcare models lack effective means of communicating patients' drug therapies upon hospital discharge. Up to $45 \%$ of discharge medications are first prescribed in hospital, which increases the risk of patient adverse events if adequate medication education is not received.

Objectives: The purpose of the study was to propose a feasible and sustainable patient-centered medication discharge education process for atrial fibrillation (AF) patients within the Cardiac Surveillance Unit (CSU) at the Regina General Hospital. The objectives were:

1. To identify the current medication discharge education process.

2. To elicit the enablers for the provision of patient medication discharge education.

3. To elicit the barriers for the provision of patient medication discharge education.

4. To determine what medication discharge education is essential for patients to receive to promote adherence and safety.
5. To provide suggestions for further consideration of a multidisciplinary medication discharge education process.

Study Design and Methods: A single multidisciplinary focus group including pharmacists, nurses, and a social worker, was conducted.

Results: Thematic coding was used to identify the current process, enablers, barriers, and essential information, and to propose the following suggestions: (1) All CSU providers should be responsible for providing patient education; (2) Use pharmacy technology to identify patients for education; (3) Provide consistent written and verbal information to increase patient understanding; (4) Facilitate patient access to discharge medications; (5) Improve inpatient and outpatient provider communication; (6) Expand use of the Cardiac Teaching Document to all CSU members; (7) Create an AF pathway; (8) Develop additional education tools and house materials online.

Conclusion: The ideas proposed build upon the current process and integrate aspects of discharge medication education that have been successful for CSU or other teams. Implementation of these suggestions may improve both patient understanding and adherence to $\mathrm{AF}$ medications.

\section{How Do National Clinical Pharmacy Key Performance Indicators Align With Top-Ranked Consensus Selection Criteria?}

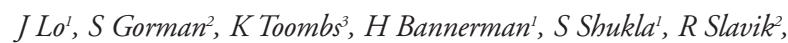
B Semchuk', D Doucette, W Chan', N Benninger', N MacKinnon ${ }^{6}$, C Bell, J Slobodan ${ }^{8}$ C Lyder ${ }^{2}$, T Pereira ${ }^{8}$, A Bjelajac-Mejia ${ }^{10}$,

$S$ Spina ${ }^{I I}$, O Fernandes ${ }^{I, 12}$

${ }^{1}$ Leslie Dan Faculty of Pharmacy, University of Toronto, Toronto, ON

2Interior Health Authority, Kelowna, BC

${ }^{3}$ Capital Health, Halifax, NS

${ }^{4}$ Regina Qu'Appelle Health Region, Regina, SK

${ }^{5}$ Horizon Health Network, Moncton, NB

${ }^{6}$ University of Cincinnati, Cincinnati, $\mathrm{OH}$

${ }^{7}$ Mount Sinai Hospital, Toronto, $O N$

${ }^{8}$ Alberta Health Services, Red Deer, AB

${ }^{9}$ Canadian Society of Hospital Pharmacists, Edmonton, AB/Ottawa, ON

${ }^{10}$ The Hospital for Sick Children, Toronto, ON

${ }^{11}$ Vancouver Island Health Authority, Victoria, BC

${ }^{12}$ University Health Network, Toronto, ON

Rationale: National consensus candidate clinical pharmacy key performance indicators (cpKPIs) and selection criteria (Slavik-11) representing pan-Canadian cpKPI ideal attributes have been established. A Slavik-11 scoring scale was designed to facilitate a balanced assessment of competing perspectives for individual cpKPIs.

Description: Objectives: 1) To report national Delphi panelist priority ranking of consensus cPKPI selection criteria and the top-five cpKPIs for each of the top-five selection criteria, 2) to determine how panelist ratings of candidate cpKPIs based on individual top-ranked Slavik-11 criteria align with the overall ratings and consensus cpKPIs. An electronic survey instrument using a 9-point Likert scale was used by the panel $(n=26)$ to rate each candidate cpKPI on individual Slavik-11 criteria and assign an overall score. The pre-defined consensus threshold was reached when $\geq 75 \%$ of panelists assigned the candidate cpKPI an overall rating of $\geq 7$. Panelists also ranked the importance of each Slavik-11 criterion in advancing clinical pharmacy practice to improve the quality of patient care. The five candidate cpKPIs with the highest mean ratings for each Slavik-11 criterion were compared to the consensus cpKPIs. Overall scores were compared to Slavik-11 composite means. 
Evaluation: The top-five Slavik-11 criteria were: 1) high quality evidence, 2) clinically important outcomes, 3) best suited to pharmacist role, 4) attributable to direct patient care, and 5) specific to a pharmaceutical care process. The top-five candidate cpKPIs for these categories varied from the consensus cpKPIs. However, average overall ratings of candidate cpKPIs correlated well with the composite mean Slavik-11 ratings for each of the candidate cpKPI $(\mathrm{R}=0.973$, $\mathrm{P}<0.0001)$.

Importance: The Slavik-11 consensus criteria appear to align well with the final-eight consensus cpKPI. Utilization of the Slavik-11 scoring scale in selecting national cpKPIs provides a systematic approach to ensure that the entire spectrum of predefined ideal attributes is considered.

\section{Handbook for a Pilot Study to Reduce Potential Hospitalizations due to Preventable Drug-Drug Interactions}

\section{CSHP2@15}

Atsushi Kawano, Certina Ho

Institute for Safe Medication Practices Canada (ISMP Canada), Toronto, ON

Rationale: Hospital reports on medication incidents suggest $37-51 \%$ of reported adverse drug events, including drug-drug interactions (DDIs), may have been prevented with appropriate interventions. The Institute of Clinical Evaluative Sciences conducted population-based studies examining the association between specific DDIs and hospitalizations.

Description of Concept: This study intends to compile a list of evidence-based DDIs with association to an increased risk of hospitalizations and develop a treatment algorithm handbook to facilitate pharmacists or clinicians in ambulatory care in identifying and offering recommendations to prescribers to prevent these DDIs.

Steps Taken: A comprehensive literature search was conducted and articles were selected based on relevant DDIs that were associated with an increased risk of hospitalization. Evidence-based treatment algorithms were created to suggest alternative therapeutic options for three common community infections - Group A -hemolytic Streptococcus pharyngitis, outpatient community-acquired pneumonia, and uncomplicated lower urinary tract infections.

Evaluation: Evidence-based DDIs identified in this study involved either a macrolide or trimethoprim-sulfamethoxazole. In all cases, the evidence supported an alternative to either antibiotic for selected community infections. Older persons were underrepresented in trials evaluating antibiotic therapy for community infections. Selecting an appropriate antibiotic required using data derived primarily from children and adults. A treatment algorithm handbook was created for clinicians in ambulatory care.

Importance to Practice: The list of evidence-based DDIs with association to an increased risk of hospitalizations identified in this study was made available to all pharmacists via the Ontario College of Pharmacists quarterly publication, Pharmacy Connection, in Spring 2013. Pharmacists/clinicians have the option of using the treatment algorithm handbook developed in this project to help resolve and prevent these DDIs.

\section{What Are the Appropriate Clinical Pharmacy Key Performance Indicators for Hospital Pharmacists? CSHP2D15}

Olavo Fernandes', Sean K Gorman ${ }^{2}$, Richard S Slavik², William M Semchuk', Douglas Doucette ${ }^{4}$, Heather Bannerman', Jennifer Lo, Simone Shukla', Winnie Chan', Natalie Benninger', Neil J MacKinnon', Chaim M Bell, Jeremy Slobodan',

Catherine Lyder ${ }^{9}$, Peter J Zed ${ }^{10}$, Kent Toombs ${ }^{I I}$

${ }^{1}$ University Health Network, Toronto, $O N$

Interior Health Authority, Kelowna, BC

${ }^{3}$ Regina Qu'Appelle Health Region, Regina, SK

${ }^{4}$ Horizon Health Network, Moncton, NB

${ }^{5}$ University of Toronto, Toronto, $O N$

${ }^{\circ}$ University of Arizona, Tucson, $A Z$

${ }^{7}$ Mount Sinai Hospital, Toronto, $O N$

${ }^{8}$ Alberta Health Services, Red Deer, AB

${ }^{9}$ Canadian Society of Hospital Pharmacists, Edmonton, AB/Ottawa, ON

${ }^{10}$ University of British Columbia, Vancouver, BC

${ }^{11}$ Capital District Health Authority, Halifax, NS

Rationale: Key performance indicators are quantifiable measures of quality. Clinical pharmacy key performance indicators (cpKPI) aim to advance clinical pharmacy practice and improve patient care. There are currently no published, systematically-derived cpKPI.

Objectives: To systematically develop a core set of national cpKPI.

Study Design and Methods: A cpKPI working group systematically and sequentially established a cpKPI consensus definition, 8 evidencederived cpKPI critical activity areas, 26 candidate cpKPI, and 11 cpKPI ideal attributes in addition to 1 overall consensus criterion. Over a 3-month period, 26 clinical pharmacists and hospital pharmacy leaders participated in a 3-round modified Delphi survey. Using an Internet-based, pre-tested survey instrument, panelists independently rated the 26 candidate cpKPI using the $11 \mathrm{cpKPI}$ ideal attributes and 1 overall consensus criterion on a 9-point Likert scale. A meeting was facilitated between rounds 2 and 3 to debate the merits of each candidate cpKPI and clarify wording. Consensus was reached if 75\% or more of the panelists assigned a score of 7-9 on the consensus criterion during the third Delphi round.

Results: All panelists completed the 3 Delphi rounds and 25/26 (96\%) attended the meeting. Eight candidate cpKPI of activities performed by pharmacists met the consensus definition after the third Delphi round: 1) performing admission medication reconciliation (including best possible medication history); 2) participating in inter-professional patient care rounds; 3) completing pharmaceutical care plans; 4) resolving drug therapy problems; 5) providing in-person disease and medication education to patients 6) providing discharge patient medication education; 7) performing discharge medication reconciliation; and 8) providing bundled, proactive direct patient care activities.

Conclusions: A Delphi panel of hospital pharmacists was successful in determining 8 consensus cpKPI. Measurement and assessment of these cpKPI, which are believed to be generalizable to other health systems, will serve to advance clinical pharmacy practice and improve patient care. 


\section{Démarche pour la mise à niveau d'un secteur de soins pharmaceutiques : le cas de la chirurgie pédiatrique}

\section{CSHP2 215}

Aurélie Guérin', Maxime Thibault', Christina Nguyen ${ }^{l}$, Denis Lebel', Jean-François Bussières ${ }^{1,2}$

${ }^{I}$ Département de pharmacie et Unité de recherche en pratique pharmaceutique, Centre hospitalier universitaire Sainte-Justine, Montréal, QC ${ }^{2}$ Faculté de pharmacie, Université de Montréal, Montréal, QC

Justification : Depuis deux décennies, les pharmaciens hospitaliers exercent majoritairement de façon décentralisée dans les programmes de soins. On reconnait les difficultés inhérentes à la hiérarchisation de ces programmes et des activités pharmaceutiques lorsque les ressources disponibles sont insuffisantes.

Objectif : Mettre à jour le niveau de pratique utilisé en soins pharmaceutiques en chirurgie pédiatrique.

Méthodologie et démarche : Il s'agit d'une étude descriptive avec revue documentaire menée dans un centre hospitalier universitaire mère-enfant canadien. La démarche de mise à niveau proposée comporte trois étapes soit une revue de la documentation, une description du profil du secteur et une description de la mise à jour du niveau de pratique.

Résultats : Des 137 articles recensés, 15 ont été retenus. Nous ne recensons aucune activité pharmaceutique spécifique reposant sur des données de très bonne qualité (A). Nous recensons cinq activités pharmaceutiques reposant sur des données de bonne qualité (B) et sept comportant un niveau de preuve insuffisant (C, D). Toutefois, plusieurs auteurs ont décrit l'évolution du rôle clinique du pharmacien en chirurgie. Une revue de l'activité pharmaceutique en 2012-2013, a permis de recenser 2,89 interventions/heure de soins décentralisé (40\% modification de la thérapie, 26\% continuité des soins, 13\% conseils/histoires) pour un total de 17867 admissions. La mise à jour envisagée du secteur de pratique inclut l'implantation de bilan comparatif médicamenteux avec profil web sur l'intranet pour l'ambulatoire, la consultation systématique via tablette numérique à l'étage de tous les dossiers pharmacologiques informatisés, la révision des protocoles et des pratiques afin de standardiser la pharmacothérapie, la production de plans de soins pharmaceutiques pour transmission au pharmacien communautaire pour les pharmacothérapies complexes, etc.

Conclusion : Il existe peu de données sur la hiérarchisation des programmes de soins et des activités pharmaceutiques. Cette étude décrit une démarche de mise à jour en chirurgie pédiatrique.

\section{Stability of Clobazam $1 \mathrm{mg} / \mathrm{mL}$ in Extemporaneously Compounded Oral Suspensions Using Oral Mix Vehicle in PET, PVC, Glass Bottles and Plastic Unit-Dose Syringes}

Blake E Ziegler, Andrea Walsh, Scott E Walker, Shirley Law, Karen Lingertat-Walsh, Pacita Sales

Department of Pharmacy, Sunnybrook Health Sciences Centre, and Department of Pharmacy, The Hospital For Sick Children, Toronto, ON

Background and Rationale: An oral liquid formulation of clobazam is not commercially available in Canada and has not been previously studied. An extemporaneous oral liquid formulation is required for administration to patients who cannot swallow intact tablets.

Objective: To evaluate the stability of clobazam $1 \mathrm{mg} / \mathrm{mL}$ prepared in Oral Mix vehicle and stored in 3 types of containers (amber glass, amber polyethylene terephthalate [PET] and amber polyvinylchloride [PVC]) over 91 days at $4^{\circ} \mathrm{C}$ and $23^{\circ}$ and polypropylene oral plastic syringes at $23^{\circ} \mathrm{C}$ only.

Methods: A reverse-phase stability-indicating liquid chromatographic method was validated before the study. Three separate batches of clobazam suspension $1 \mathrm{mg} / \mathrm{mL}$ were prepared with Oral Mix. Fifty $\mathrm{mL}$ aliquots of the suspension were stored in $100 \mathrm{~mL}$ bottles (amber glass, amber PET, or amber PVC). Half of the bottles from each container type were stored at $23^{\circ} \mathrm{C}$ and the other half at $4^{\circ} \mathrm{C}$. On study days $0,2,7,14,21,28,42,56,72$ and 91 , clobazam concentration was determined in samples drawn from bottles stored at each temperature in each type of container. Oral syringes, filled with $2 \mathrm{~mL}$ suspension, were stored at $23^{\circ} \mathrm{C}$ and tested on days $0,2,7,21,42$ and 91 .

Results: The concentration of clobazam $1 \mathrm{mg} / \mathrm{mL}$ in Oral Mix in all study samples from bottles and oral syringes remained within $4 \%$ of the initial concentration. Based on the fastest degradation rate with $95 \%$ confidence, on day 91 suspensions stored in bottles at $23^{\circ} \mathrm{C}$ and $4^{\circ} \mathrm{C}$ had between $91-94 \%$ and $95-96 \%$ remaining respectively. Oral syringes at $23^{\circ} \mathrm{C}$ had $89 \%$ remaining on day 91 .

Conclusions: Using the fastest degradation rate, clobazam $1 \mathrm{mg} / \mathrm{mL}$ oral suspension in Oral Mix in all bottle types retained more than 95\% of the initial clobazam concentration at $4 \mathrm{C}$, more than $91 \%$ at $23 \mathrm{C}$ and only $89 \%$ when stored in oral syringes on day 91 .

\section{Stability of Domperidone $5 \mathrm{mg} / \mathrm{mL}$ in Extemporaneously Compounded Suspensions Using Oral Mix Vehicle in PET, PVC, Glass Bottles and Plastic Oral Unit-Dose Syringes}

Karen Lingertat-Walsh, Shirley Law, Scott Walker, Pacita Sales Department of Pharmacy, Sunnybrook Health Sciences Centre, and Department of Pharmacy, The Hospital For Sick Children, Toronto, ON

Background and Rationale: Domperidone $1 \mathrm{mg} / \mathrm{mL}$ and $10 \mathrm{mg} / \mathrm{mL}$ in ORA-Blend was studied previously in PVC bottles only. Oral Mix is a new vehicle manufactured in Canada, similar in composition to ORA-Blend. Stability of domperidone $5 \mathrm{mg} / \mathrm{mL}$ using Oral Mix was determined using different bottle types and plastic oral syringes which has not been previously done.

Objective: To evaluate the stability of domperidone $5 \mathrm{mg} / \mathrm{mL}$ suspension prepared in Oral Mix and stored in 3 types of containers (amber glass, amber polyethylene terephthalate [PET] and amber polyvinylchloride [PVC]) over 91 days at $4^{\circ} \mathrm{C}$ and $23^{\circ} \mathrm{C}$ and polypropylene oral syringes at $23^{\circ} \mathrm{C}$ only.

Methods: A validated reverse-phase stability-indicating liquid chromatographic method was used. Three separate batches of domperidone $5 \mathrm{mg} / \mathrm{mL}$ suspension were prepared in Oral Mix. Seventy-five $\mathrm{mL}$ aliquots of the suspension were stored either in amber PVC and amber glass $(250 \mathrm{~mL}$ bottles), amber PET (100mL bottles) or $1.5 \mathrm{~mL}$ in polypropylene oral syringes. Half the bottles of each container type were stored at $23^{\circ} \mathrm{C}$ and the other half at $4^{\circ} \mathrm{C}$. On study days $0,1,2,4,7,10,14,21,28,35,42,49,63,77,91$ domperidone concentration was determined in samples from bottles stored at each temperature in each container type and from polypropylene oral syringes.

Results: The concentration of domperidone $5 \mathrm{mg} / \mathrm{mL}$ in Oral Mix in all study samples from bottles and oral syringes remained within $6 \%$ and $7 \%$ of the initial concentration. Based on the fastest degradation rate with $95 \%$ confidence, on day 91 suspensions stored in bottles at 23C and 4C had between $88-92 \%$ and $92-93 \%$ remaining respectively. Oral syringes at $23 \mathrm{C}$ had only $87 \%$ remaining. 
Conclusion: Using the fastest degradation rate, domperidone $5 \mathrm{mg} / \mathrm{mL}$ oral suspension in Oral Mix in all bottle types retained more than $92 \%$ of the initial domperidone concentration at $4^{\circ} \mathrm{C}$, more than $88 \%$ at $23^{\circ} \mathrm{C}$ and only $87 \%$ when stored in polypropylene syringes on day 91.

\section{IV to PO Stepdown Interventions in a Community Hospital Without an Infectious Disease Physician \\ CSHP2D15}

Andrea Wist, Gayathri Radhakrishnan, Kayleigh Curts

Bluewater Health, Sarnia, Ontatio

Rationale: This project demonstrates the successes (Pharmacoeconomics and Time) of implementing IV to PO antibiotic stepdown involving a multidisciplinary approach, as part of a stewardship program in line with Accreditation Standards.

Description: Bluewater Health (BWH) is a 326 bed community hospital without an Infectious Disease Physician. BWH had an automatic IV to PO stepdown policy only for 5 antibiotics since 2007. In this project, all IV antibiotics on formulary were included for review.

Implementation: All patients initiated on IV antibiotics in Med Telemetry unit (MEDT) were reviewed on Day 3 of antibiotic therapy. Patients were excluded if they transferred in or out of MEDT during their IV antibiotic therapy. The project period covered 4 weeks in May-June 2012. The pharmacist reviewed the patient's clinical status to determine eligibility for stepdown. If patient met eligibility, the pharmacist notified the clinician of an appropriate PO alternative. Follow up was done the next day to determine if the suggestion was accepted, partially accepted or rejected. IV to PO stepdown data was also captured when there was no pharmacist involvement. The amount of time spent in reviewing patients and follow up was also collected. Upon completion, the cost of total PO antibiotic therapy was subtracted from the cost of the anticipated full duration of IV therapy (if $\mathrm{PO}$ conversion was not completed) to calculate cost savings.

Evaluation: 18 patients (who had a total of 20 antibiotic orders) were included.

Table 1: Summary of IV to PO outcomes

\begin{tabular}{ll}
\hline \# of orders ineligible for IV $\rightarrow$ PO $(15 \%)$ & 3 \\
\# of orders discontinued $(20 \%)$ & 4 \\
\# of orders discontinued with pharmacist & $(3)$ \\
and physician involvement & \\
\# of orders discontinued with physician involvement only & $11)$ \\
\# of orders eligible for IV $\rightarrow$ PO $(50 \%)$ & 10 \\
\# of orders changed to po with pharmacist & $(6)$ \\
$\quad$ and physician involvement & \\
\# of orders changed to po with physician involvement only & $(3)$ \\
\# of orders continued as IV & (1)
\end{tabular}

Antibiotics reviewed: Ceftriaxone, Ceftazidime,

Moxifloxacin, Cefazolin, Azithromycin, Ciprofloxacin,

Metronidazole.

Average amount of time required to review patients who were eligible for IV to PO:

Cost savings by switching to $\mathrm{PO}$

Relevance to Practice: This project adds to current literature on IV to PO antibiotic conversions, creating a template on how it can be accomplished without an Infectious Disease Physician.

\section{Update of the Canadian Labels for Antipsychotic Drugs Following a Review of the Evidence on the Risk of Venous Thromboembolism Associated with the Use of These Medications}

\section{David Duguay, Co Pham, Marc Berthiaume}

Marketed Pharmaceuticals and Medical Devices Bureau, Marketed

Health Products Directorate, Health Canada

Rationale: Venous thromboembolism (VTE) has been reported with antipsychotics use in numerous published case reports and in several studies since the introduction of phenothiazines in Canada in the 1950 's.

Objectives: The purpose of the review conducted by Health Canada was to evaluate the association between the risk of VTE and the utilization of antipsychotics as a class, and to recommend strategies to mitigate risk as needed.

Study Design and Methods: Health Canada conducted a review of cases of VTE with antipsychotic drugs reported in the Canada Vigilance database between January $1^{\text {st }}, 1965$ and May 31, 2011, and a review of published studies and case reports related to VTE and antipsychotics.

Results: As of May 31, 2011, the CanadaVigilance database contained a total of 140 unique reports of VTE associated with antipsychotic drugs (most cases were reported with clozapine [69\%]* and some with olanzapine, risperidone, quetiapine, haloperidol, flupenthixol, and loxapine). A literature search from 1948 to September 9, 2011 identified over 80 published case reports of VTE suggestive of an association with antipsychotic drugs, in addition to 14 pharmacoepidemiology studies on this specific issue. The review demonstrated a consistent trend in studies suggesting an increased risk of VTE with exposure to antipsychotic drugs.

Conclusion: The evaluation of the risk of VTE gathered from epidemiological studies, published case reports, and reports of adverse drug reactions in pharmacovigilance databases has resulted in a recommendation to update the Canadian Product Monographs of all antipsychotic drugs.

*Clozapine is available in Canada only through a restrictive distribution system. This drug is under an increased level of scrutiny compared to other antipsychotics.

\section{Pharmacists Joining a Multi-Disciplinary Specialty Private Practice}

Kerry Wilbur', Jason Kur

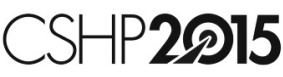

${ }^{\prime}$ College of Pharmacy, Qatar University, Doha, Qatar

${ }^{2}$ Artus Health Centre and University of British Columbia, Vancouver, BC

Rationale: Pharmacists have assumed medication management roles in both inpatient hospital and outpatient primary health care settings; however, proliferation of pharmacists in private practices is not yet pervasive. (CSHP 2015 Objective 2.1). Established multidisciplinary teams may not recognize the potential contributions of pharmacists joining these settings, which may contribute to barriers to integration and patient care.

Objective: Explore the attitudes and perceptions among multidisciplinary members of a private rheumatology clinic towards the skills and responsibilities of a pharmacist joining their practice.

Methods: The physicians, nurse, physiotherapist and office administrators of a private rheumatology clinic were invited to 
participate in focus group and semi-structured interviews to discuss their understanding of pharmacist skills and knowledge and how they would foresee a pharmacist assuming patient care responsibilities in their current setting. Sessions were audio recorded and transcribed verbatim. Thematic content analysis of the data was supported with nVivo10 software.

Results: Discussions with two physicians, the nurse, the physiotherapist and one office administrator were conducted. Concepts related to two key themes emerged from the seeding questions and included positively viewed pharmacist roles broadly related to activities that encompass provision of drug information and management of medications. Less enthusiasm was found for pharmacist documentation of their patient assessments and care plans in the shared medical record. Disparate views arose regarding anticipated volume of pharmacist responsibilities and independent follow up with patients. Most members were not comfortable with pharmacists conducting physical assessments and impressed the need for a team member who could adapt to variations in workflow preferences across rheumatologists in the practice.

Conclusions: Overall, existing multidisciplinary staff exhibited favourable attitudes towards a pharmacist joining their practice setting, but expressed conflicting concerns regarding sufficient workload to support a full-time position.

\section{Impact and Role of Pharmacists in Cystic Fibrosis \\ Aurélie Guérin', Denis Lebel', Jean-François Bussières ${ }^{l, 2}$ \\ 'Pharmacy Department and Pharmacy Practice Research Unit, Centre hospitalier universitaire Sainte-Justine, Montréal, QC \\ ${ }^{2}$ Faculty of Pharmacy, Université de Montréal, Montréal, QC}

Rationale: Cystic fibrosis is an autosomal recessive genetic disorder that affects the lungs, the pancreas, the liver and the intestine. The pharmacotherapy contributes to a better quality of life, reduced hospitalizations and prolonged survival.

Objective: The aim of this study was to review the literature on the impact and the role of pharmacists in cystic fibrosis.

Study Design and Methods: A Web portal about the evidences of the impact and the role of pharmacists in specific diseases, programs of care or pharmaceutical activities was developed. A literature search on Pubmed® was conducted: pharmacist OR clinical pharmacy OR pharmaceutical care AND cystic fibrosis. Articles about the role and the impact of pharmacists in cystic fibrosis in French and English from 1990-2013 were included. For each article included in the analysis, key indicators that document the impact of pharmacist with statistical analysis and the role of pharmacists with only quantitative or qualitative metrics were identified. All relevant pharmaceutical activities in that context were also identified.

Results: A total of 217 articles were initially identified. Only four relevant articles were included in our analysis Nine key indicators of the impact were identified: drug level costs, dosing adjustment costs, costs/admission, total costs, length of stay, quality of life, levels/patient, days to goal of therapy and courses with pharmacokinetics goals. Eight of the nine indicators showed a positive impact of the pharmacist in cystic fibrosis. Twenty-four key indicators about the role of pharmacists were identified. Amongst the pharmaceutical activities, pharmacists were providing medication reconciliation, patient counseling, drug therapy evaluation, pharmacokinetics consultation, drug information and medical rounds.

Conclusion: There are limited data published about the role of pharmacists in cystic fibrosis. While it seems relevant to support such clin- ical implication, pharmacists involved in that program of care should better document and evaluate their impact.

\section{Evaluation of a Change in Clinical Pharmacist Practice Model in a Community Hospital \\ CSHP2D15}

Monica Lee, Jenny Chiu, Saadia Fazil, Edith Rolko

North York General Hospital, Toronto, ON

Rationale: North York General is a 420-bed community hospital staffed with 23 full-time equivalent (FTE) clinical pharmacists. Historically, clinical pharmacists rotated through different areas and were not assigned to specific units. It was determined that a change from this rotation-based model to a designated unit-based model would enable pharmacists to develop clinical expertise and improve service to patients and staff.

Description and Steps Taken: Clinical pharmacists were asked to provide the units they preferred to service. The pharmacy leadership group then discussed and finalized assignments. The designated unit-based model was implemented in early 2012. A one-year post-implementation survey was developed to evaluate pharmacists' view of how this change has affected job satisfaction, workload and contribution to patient care. Clinical pharmacists who worked 30 hours per week or more, and have practised in both models for at least one year were invited to participate.

Evaluation: An on-line survey consisting of nine questions was sent to 15 pharmacists, of which 14 (93\%) responded. Eleven (79\%) pharmacists indicated that their job satisfaction has improved with the new model. All respondents agreed that they would better cultivate clinical expertise with the designated unit-based model. However, most considered the rotation-based model to be associated with the development of a broader scope of skills and knowledge. Interestingly, $9(64 \%)$ respondents felt less comfortable covering units that were not their designated units. With respect to workload, 6 (43\%) felt that workload has increased with the new model, while 7 (50\%) perceived no change. Thirteen $(93 \%)$ pharmacists believed the quality of care provided with the designated unit-based model to be superior to the rotation-based model.

Importance: Overall, clinical pharmacists considered the change in practice model to be positive. Further studies should be conducted to examine how patients and staff perceive this

\section{Médias sociaux, comportements en ligne et pharmaciens : lignes directrices et réflexions}

Aurélie Guérin, Denis Lebel, Jean-François Bussières

Département de pharmacie et Unité de recherche en pratique pharmaceutique, Centre hospitalier universitaire Sainte-Justine, Montréal, Québec

Justification : Avec l'émergence de nombreux outils de communications, la place des médias sociaux comportent de nombreuses opportunités et défis pour les pharmaciens et ses collaborateurs.

Objectifs : Recenser et comparer les lignes directrices et normes pouvant contribuer à l'encadrement des comportements en ligne professionnels.

Méthodologie et démarche de l'étude : Étude descriptive. À partir d'une revue documentaire, nous avons identifié les principales lignes directrices de société savantes médicales et pharmaceutiques publiées 
sur les médias sociaux. Nous avons ensuite comparé le contenu et la portée des lignes directrices proposées.

Résultats : Nous avons recensé 11 lignes directrices de 11 sociétés savantes dont quatre canadiennes, trois américaines, deux britanniques et une australienne. Dix sociétés savantes sont médicales et une pharmaceutique. Treize paramètres ont été extraits des lignes directrices. Quatre paramètres font davantage consensus à savoir la protection des renseignements personnels des patients, le respect de la frontière professionnel-patient, l'évitement de la communication des renseignements personnels sur soi et la saisie des enjeux des communications en ligne. Il existe peu de balises en pharmacie et les pharmaciens doivent être sensibilisés aux opportunités et enjeux reliés aux comportements en ligne.

Conclusion: Avec l'émergence de nombreux outils de communications et le développement des médias sociaux, 11 sociétés savantes ont publié des lignes directrices pour encadrer le comportement en ligne des professionnels dans le domaine de la santé.

Pour le tableau afférent à ce résumé, consultez l'annexe publiée au www.cjhp-online.ca/index.php/cjhp/issue/view/100/showToc

\section{Experience with Dexmedetomidine in a Medical Intensive Care Unit at a Community Teaching Hospital}

\section{CSHP2D15}

Bonnie Thien

North York General Hospital, Toronto, ON

Rationale: Sedative agents are commonly used in mechanically ventilated patients to control agitation. These include opioid analgesics, benzodiazepines, and propofol, all of which can cause delirium and respiratory depression. Dexmedetomidine is an alpha-2 adrenergic agonist that does not cause respiratory depression and may be associated with a lower risk of delirium. As a result of its favourable profile, our institution has recently added dexmedetomidine to the drug formulary. However, due to the high cost of this drug, strict guidelines have been established for its use, which outline specific indications, contraindications, and maximum duration of therapy.

Objective: To evaluate adherence to hospital guidelines for the use of dexmedetomidine by clinicians.

Methods: We conducted a retrospective chart review of all patients initiated on dexmedetomidine in the medical intensive care unit (ICU) from January 1, 2012 to December 31, 2012. The primary endpoint was overall concordance with hospital guidelines, including the indications for which dexmedetomidine was prescribed; the presence of any contraindications; and the total duration of therapy. Descriptive statistics was used to analyze the data.

Results: Over the 1-year period, 13 patients were prescribed dexmedetomidine. All patients had one or more of the approved indications. However, 9 patients $(69 \%)$ also had 1 or more contraindications to the use of dexmedetomidine. In addition, 7 patients $(46 \%)$ remained on the drug for longer than the recommended duration of 72 hours. Overall, none of the dexmedetomidine use was in complete concordance with hospital guidelines.

Conclusions: The use of dexmedetomidine was discordant with guidelines established by our institution with respect to indications, contraindications, and duration of therapy. It is necessary to identify barriers to adherence, revise the guidelines, and re-educate the ICU team.

\section{Adherence to Hospital Sepsis Treatment Guidelines} CSHP2ه15

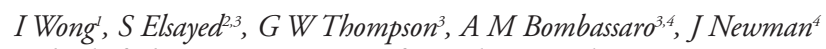
${ }^{1}$ School of Pharmacy, University of Waterloo, Waterloo, ON ${ }^{2}$ Departments of Microbiology \& Immunology and Pathology \&. Laboratory Medicine, Western University, London, $O N$ ${ }^{3}$ Department of Medicine, Western University, London, $O N$ ${ }^{4}$ Pharmacy Services, London Health Sciences Centre, London, ON

Rationale: A quality improvement initiative was undertaken to examine and characterize aspects of antimicrobial therapy in patients with sepsis or severe sepsis/septic shock.

Objectives: The primary objective was to evaluate empiric antimicrobial prescribing for sepsis and severe sepsis/septic shock as a surrogate of adherence to hospital treatment guidelines. The secondary objectives were to determine the timing of administration, adequacy of the spectrum of initial therapy and frequency of modifications.

Study Design and Methods: Retrospective chart review was performed using a convenience sample of sequentially selected records with a diagnosis of sepsis or septic shock. Adherence (full and partial) was evaluated by comparing the empiric regimen (antibiotic, dose, route, timing) to the hospital treatment guidelines. Adequacy of the initial regimen was determined using microbiology results and guideline/expert consensus when the former was inconclusive. Opportunity for spectrum modification was assessed by expert consensus.

Results: Seventy charts were reviewed, of which 66 met the inclusion criteria (34 sepsis, 32 severe sepsis/septic shock). Regimens prescribed for 35 patients were evaluable for adherence. The most common reason for exclusion from the adherence analysis was a suspected site of infection not addressed in the guidelines (22/31). Adherence of the prescribed regimen to the guidelines was found in 15/35 (43\%) with only 3 of these being fully adherent. Antibiotics were administered within 1 hour of the diagnosis of severe sepsis/septic shock in 15/32 (47\%) patients. The initial spectrum was deemed adequate in 49/66 (74\%) patients. The opportunity for spectrum modification existed in 20/29 cases in which no change was made.

Conclusions: Several areas for improvement in the sepsis initiative at this institution were identified. A minority of evaluable patients received empiric antimicrobial therapy adherent to the treatment guidelines. Gaps were noted in the scope of the guidelines, timely antimicrobial administration, adequacy and modification of the initial spectrum.

\section{Drug Shortages in Health Care Institutions: Perspectives in Early 2014}

Isabelle Barthélémy, Denis Lebel, Jean-François Bussières

Centre hospitalier universitaire Sainte-Justine, Montréal, QC

Rationale: The drug shortage crisis represented a total opportunity cost of more than half a million dollars for five Quebec University Hospital Centers and contributed to the postponement of pharmaceutical activities.

Objectives: To describe drug shortages for the period of 2006-2013.

Study design and methods: Retrospective study. Drug shortages data have been collected from the Fridaypm.com Website since 2006. The number of drug shortages, average duration, number of manufacturers involved and therapeutic classes involved were collected for each year. 
Results: From 2006-2013, the annual number of drug shortages was of, respectively, 493,400,441, 679, 429, 1081 and 497. A 46\% decrease was observed in 2012-2013 compared with 2011-2012. An increase in the average duration of drug shortages was observed, from $108 \pm 130$ days in 2006-2010, to $103 \pm 85$ in $2011-2012$ and to $168 \pm 153$ in 2012-2013. The number of manufacturers involved in drug shortages decreased from 58 in 2011-2012 to 38 in 2012-2013. Most of the drug shortages in 2012-2013 involved generic drug manufacturers, which represented $85 \%$ of the total number of drug shortages and $87 \%$ of the total number of drug-shortage days. Most therapeutic classes were affected by shortages in 2012-2013. The main drug classes affected were central nervous system agents (23\%), cardiovascular drugs (13\%) and anti-infective agents. The percentage of parenteral formulations among the total number of drug shortages increased from $33 \%$ in $2011-2012$ to $36 \%$ in 2012-2013. In terms of duration, parenteral formulations drug shortages accounted for and increased from $37 \%$ of days in 2011-2012 to $47 \%$ in 2012-2013.

Conclusion: A decrease in the number of drug shortages was observed for 2012-2013, but there was an increase in the percentage of parenteral formulations drug shortages and duration. There was also an increase in the number of drug shortages involving generic manufacturers.

\section{Adverse Drug Reaction-Related Hospitalizations among Seniors, 2006 to 2011}

Michele Arthur, Michael Gaucher

Canadian Institute for Health Information, Ottawa, ON

Rationale: Adverse drug reactions (ADRs) are defined by the World Health Organization as adverse effects of a drug that was properly administered in the correct dose, for therapeutic or prophylactic use. Seniors are at greater risk for ADRs, as well as other types of drugrelated adverse events, due to the number of drugs they take, their higher prevalence of certain chronic conditions and age-related changes in the body.

Objectives: This analysis examines the prevalence of ADR-related hospitalizations among seniors. It also examines the drugs and the types of reactions most commonly associated with these hospitalizations.

Study Design and Methods: This analysis used data from the Discharge Abstract Database and Hospital Morbidity Database from all Canadian provinces. Hospitalizations due to ADRs were identified using ICD-10 diagnosis and external cause codes.

Results: In 2010-2011, 1 in 200 Canadian seniors was identified as having an ADR-related hospitalization (five times more than non-seniors). Anticoagulants were the drug class most commonly associated with ADR-related hospitalizations. The most common diagnosis associated with anticoagulants was bleeding. Other drugs commonly associated with ADR-related hospitalizations were antineoplastic drugs and opioids and related analgesics. The most common diagnosis associated with ADR-related hospitalizations due to antineoplastic drugs was neutropenia, while the most common diagnosis associated with opioid-related hospitalizations was constipation.

Conclusion: Many of the commonly observed ADRs were well known reactions. Although it is not always possible to prevent an ADR from occurring, patient monitoring and education are important to ensure that ADRs can be identified quickly so that harm to the patient, and in turn the likelihood of hospitalization, can be minimized.

\section{Development of a Process to Ensure Timely Home Medication Access for Patients Awaiting Admission in the Emergency Department CSHP2D15}

\section{Shelita Dattani}

Queensway Carleton Hospital, Ottawa, ON

Rationale: In our Emergency Department (ED), patients frequently wait several hours before a final decision is made for admission to hospital. These patients do not consistently receive their home medications during this time as a complete Medication Reconciliation is usually not performed until the point of admission. This has great potential to compromise patient safety and efficiency of care.

Description: Our multidisciplinary task group developed a consistent and streamlined process in order to:

A) Ensure timely access to patient's home medications during longer ED stays

B) Enhance interdisciplinary communication of home medication initiation prior to admission.

Steps Taken to Implement Change: In order to minimize duplication of successful processes, our pharmacist-led multidisciplinary team evaluated a modification of our current Best Possible Medication History (BPMH) form.

This tool was designed to:

A) Trigger completion of a BPMH on patients remaining in the ED greater than four hours.

B) Provide an opportunity for the ED physician to continue home medications as needed for patients with longer ED stays.

Evaluation: A pharmacist conducted education and brainstorming sessions with ED and pharmacy staff prior to modification and implementation of the revised form. After implementation, focus group surveys revealed that modification to our BPMH form has motivated staff to complete medication reconciliation for those patients with longer ED stays and has improved patient's early access to home medications.

Relevance to Current and Future Practice: This multidisciplinarydriven process change has improved efficiency of care in the ED and through admission. It contributes to a safer and enhanced patient experience in the hospital. A formal evaluation is planned to assess the contribution of this process to improving access and communication around home medications initiated in the ED.

\section{Reduction of Polypharmacy in a Rehabilitation and Progressive Care Unit

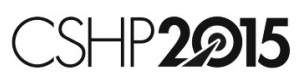

Sonia Wang, Monica Lee

North York General Hospital, Toronto, ON

Rationale: The Rehabilitation and Progressive Care Unit (RPCU) at North York General Hospital has the third highest number of medications dispensed among all medicine units. Patients in this unit are on average 85 years or older with multiple comorbidities, thus putting them at high risk of polypharmacy. The pharmacist can play an important role in minimizing inappropriate drug therapies while these patients await discharge to the next level of care.

Description and Steps Taken: A literature review was performed to establish the approach to reducing polypharmacy. Six criteria were used when considering whether a medication was unnecessary, or dose 
or duration of therapy was excessive. A documentation form was developed to guide the process of assessment and to document the intervention plan and outcomes. Medication reviews were systematically performed by the unit pharmacist within 72 hours of a patient's transfer to the RPCU. The process was piloted between January and March 2013.

Evaluation: During the 3-month period, 106 (81\%) of the 131 patients in the RPCU had their medications reviewed by the unit pharmacist. Forty-eight drug therapy problems related to unnecessary medications or excessive dose or duration were identified in 29 (27\%) patients. Of the recommendations made by the pharmacist, 44 (92\%) were accepted by the physicians. The average time between identification and resolution of a drug therapy problem was 2.4 days. Common classes of drugs identified to be unnecessary include anticoagulants, laxatives, anti-infectives, and vitamins.

Implications: Minimizing polypharmacy in the elderly patients can reduce the risk of adverse effects, and improve compliance and quality of life. The RPCU unit is a perfect setting for conducting thorough medication reviews and discontinuing any inappropriate drug therapies, since patients are closely monitored by a collaborative healthcare team. The interventions may ultimately improve patient safety and reduce cost to the healthcare system.

\section{What Doses Should Our Chemotherapy Robot Prepare?}

\section{CSHP2D15}

Rita Kwong', Roy Lee', Jeanne Chu', Tamara Rumsey

'Pharmacy, Princess Margaret Cancer Centre, Toronto, ON

${ }^{2}$ Daycare Pharmacy, Princess Margaret Cancer Centre, Toronto, ON

Objective: Manual preparation of parenteral chemotherapy doses poses inherent patient and occupational safety risks. In 2012, an IV robot was installed in our chemotherapy pharmacy that serves over 120 patients daily in our outpatient systemic chemotherapy unit and also 130 oncology inpatients. The pharmacy implementation team developed a list of criteria to identify the cancer treatment drugs to be prepared by the robot. The drug list was used to guide the ramp up during implementation.

Method: The pharmacy team analyzed the robot's efficiency factors and technological limitations to identify those drugs and doses that are technically compatible with the robot. Past chemotherapy order records were used to assess frequency of prescribing for each drug. Drug characteristics and drug distribution workflow for both just-intime and next day model of care were also reviewed. The team then developed specific selection criteria for chemotherapy drugs that would benefit from robotic production and their priority in the implementation.

Results: All chemotherapy drugs used at the cancer centre were identified and categorized based on the selection criteria that included frequency of use, supply format, presence of barcodes, drug stability, usual dose volume, applicable dispensing format, and cost. The drugs were then grouped in priority for production ramp up.

Conclusion: Thirty-three drugs used in our centre were identified as potentially compatible with the robot based on known enhancements to be released by the vendor. As of September 2013, we had implemented the drugs in our first phase with over 9 frequently dispensed hazardous drugs being prepared by the robot. Additional drugs will be added as we modify our workflow and as the known product enhancements are released.

\section{The Effect of Residual Renal Function and Other Patient Factors on Gram Positive Peritonitis Outcomes}

\author{
Rachel Whitty ${ }^{l}$, Philip Lui ${ }^{1,2}$, Alex Kiss ${ }^{3}$, Linda Dresser ${ }^{1,2}$, \\ Joanne M Bargman ${ }^{I}$ \\ ${ }^{1}$ University Health Network, Toronto, ON \\ ${ }^{2}$ Faculty of Pharmacy, University of Toronto, Toronto, ON \\ ${ }^{3}$ Sunnybrook Research Institute, Toronto, ON
}

Rationale: Gram positive organisms are the most common cause of peritonitis in patients treated with peritoneal dialysis (PD). Pharmacokinetic studies have indicated that clearance of antibiotics is higher with Continuous Cyclic Peritoneal Dialysis (CCPD) than Continuous Ambulatory Peritoneal Dialysis (CAPD), and that patients who are non-anuric have lower cefazolin concentrations compared to patients who are anuric. Few studies have examined how these and other factors affect peritonitis treatment outcomes.

Objective: The objective of this study was to determine the effect of PD modality, renal creatinine clearance, and other patient factors on gram positive peritonitis treatment outcomes in patients treated with PD.

Methods: Between 2003 and 2010, all gram positive peritonitis episodes treated with cefazolin at a large tertiary care hospital were included. A Cox proportional hazards model was used to examine the relationship between the primary outcome, time to resolution of the intraperitoneal (IP) white blood cell (WBC) count, and the following factors: PD modality, renal creatinine clearance (CrCL), PD vintage, hospitalization during peritonitis treatment, age, change in antibiotic during peritonitis treatment, and cefazolin dose per kilogram of body weight. Polymicrobial infections were excluded.

Results: There were 119 patients with 177 peritonitis episodes in this study. Lower CrCL was associated with a greater likelihood of resolution of the IP WBC count ( $\mathrm{p}=0.0002)$. Shorter duration of PD was associated with a greater likelihood of resolution $(\mathrm{p}=0.005)$. Interestingly, age was also statistically significant $(\mathrm{p}=0.03)$ with older age associated with greater resolution

Conclusions: Longer PD vintage may be associated with changes to the peritoneal membrane that leads to decreased resolution. The association between greater renal function and non-resolution suggests renal cefazolin clearance contributing to lower cefazolin concentrations and treatment failure. The unexpected association of younger age with non-resolution warrants further investigation.

\section{Can a Collaborative Community Mental Health Smoking Cessation Program Reduce Cigarette Consumption?}

\section{Kayla Cameron, Andrew Brillant}

\section{CSHP2D15}

\section{Saint John Regional Hospital, Saint John, NB}

Rationale: To contribute to the growing body of evidence supporting community based smoking cessation interventions in the mental health population. Hopes include that those living with mental illness will gain further access to alike programs where they feel accepted, satisfied, and can obtain benefits while paving their way to a healthier lifestyle.

Objectives: Determine if a smoking cessation group based program would result in a reduced number of cigarettes smoked per day. Secondary aims included changes in nicotine dependence, medication changes reflective of smoking reduction, and participant satisfaction. 
Design/Methods: Using a naturalistic design, data was collected by convenient sampling from a single community mental health recovery center at baseline, pre implementation of the smoking cessation program, and then compared at six to eight weeks into the program. Sessions involved education, information, activities, games, coping methods, support, and encouragement weekly for one hour.

Results: Number of cigarettes smoked per day was reduced from a mean of 24.13 (SD 9.471) to 1.5710 (SD 4.72) for those who remained enrolled in the program at weeks six to eight, $\mathrm{p}=0.005$. A minimum of 13 cigarettes daily decreased to a new minimum of zero. A maximum of 50 cigarettes daily dropped to a maximum of 15 . Nicotine dependence could not be assessed given number of non-smokers at data collection, there were no reflective changes to medications, and overall satisfaction of the program appeared positive.

Conclusions: The smoking cessation group intervention provided benefit to those who remained enrolled; further investigation should be explored using larger scale trials.

\section{Comparison among Atorvastatin, Rosuvastatin and Pravastatin with Focus on Efficacy and Safety Profiles}

Lolwa Barakat', Amin Jayyousi ${ }^{2}$, Abdulbari Bener ${ }^{3,4,5}$, Bilal Zuby, Mahmoud Zirie ${ }^{2}$

${ }^{1}$ Departments of Pharmacy and Clinical Pharmacy, Hamad General Hospital, Hamad Medical Corporation, Doha, Qatar

${ }^{2}$ Departments of Medicine and Endocrinology, Hamad Medical Corporation, Doha, Qatar

${ }^{3}$ Department of Medical Statistics and Epidemiology, Hamad Medical Corporation, Doha, Qatar

${ }^{4}$ Departments of Public Health and Medical Education, Weill Cornell Medical College in Qatar, Doha, Qatar

${ }^{5}$ Department of Evidence for Population Health Unit, School of Epidemiology and Health Sciences, The University of Manchester, Manchester, UK

${ }^{6}$ Pediatric Intensive Care Unit, Department of Pediatrics, Hamad Medical Corporation, Doha, Qatar

Rationale: Qatar has a high prevalence of diabetes and heart disease. Statins are commonly prescribed in diabetic patients with dyslipidemia. Data is lacking to show head to head comparison of the 3 most commonly prescribed statins in Qatar with regards to effect on serum lipid levels and safety profiles on muscular, hepatic and renal functions in diabetic patients in this country.

Objectives: To compare the effects of atorvastatin, rosuvastatin and pravastatin on lipid profile and possible impact on muscular, hepatic and renal functions.

Study Design and Methods: A retrospective observational study on 350 consecutive diabetic patients with dyslipidemia who were prescribed any of the 3 statins, during the period September 2005 September 2009. Data on lipid (serum triglycerides (TG), total cholesterol (Chol), high-density lipoprotein (HDL-C) and low-density lipoprotein (LDL-C) levels), muscular (creatinine phosphokinase), hepatic enzymes (Alanine transaminase (ALT), aspartate transaminase (AST) and alkaline phosphatase (ALP)) and renal (serum creatinine, microalbuminuria \& glomerular filtration rate) profiles were collected at baseline and after 2 years of treatment, using Electronic and paper patient records.

Results: At the end of 2 years of treatment, rosuvastatin $10 \mathrm{mg}$ reduced LDL-C by $29.03 \%$, followed by atorvastatin $40 \mathrm{mg}(22.8 \%)$ and pravastatin $20 \mathrm{mg}$ (20.3\%). Serum triglyceride level showed greatest reduction by $25.1 \%$ with rosuvastatin $10 \mathrm{mg}$. Triglyceride levels were reduced with atorvastatin $40 \mathrm{mg}$ and pravastatin $40 \mathrm{mg}$ by $21.6 \%$ and $13.5 \%$, respectively. No effects on the muscular or hepatic profiles were observed with any of these statins. Atorvastatin resulted in the least number of patients with new onset of microalbuminuria $(10.9 \%)$, followed by rosuvastatin $(14.3 \%)$ and then pravastatin $(26.6 \%)$.

Conclusion: In Qatari diabetic dyslipidemic population, the most effective statin in reducing serum LDL-C and triglyceride levels was rosuvastatin $10 \mathrm{mg}$. The safest statin in relation to renal function was atorvastin.

\section{The Path Forward: Solutions from a Province- Wide University-Health Authority Engagement Initiative}

Michael Legal, Donna Rahmatian, Kyle Collins, Patricia Gerber, Angela Kim-Sing, Peter S Loewen, Peter J Zed

Faculty of Pharmaceutical Sciences, The University of British Columbia, Vancouver BC

Rationale: It is a challenge to provide sufficient quantities of high quality experiential placements for learners in institutional settings. In recent years, this issue has become increasingly acute due to curricular and program changes in Canada. There is a critical need to develop approaches that address these challenges and ensure healthy and adaptable experiential programs in the future.

Approach: A comprehensive and rigorous methodology was employed to engage preceptors, learners and health authority leaders in British Columbia. Root causes for capacity challenges were identified and potential solutions articulated. Local feedback was combined with recommendations from the literature and best practices from across North America.

Solutions: Several broad areas of solutions were identified: health authority- faculty partnership, novel learner-preceptor models, direct faculty support for preceptors and learners, learner preparation, and enhanced experiential office. Formal, mutually beneficial partnerships between the faculty and health authorities will ensure preceptors and sites are equipped to provide optimal experiences for learners, while the faculty will benefit from a reliable supply of placements. The faculty will promote the use of pairs, small tiers and facilitated multiplacements for junior learners. Dedicated clinical faculty or protected teaching time for preceptors will address workload concerns and teaching support needs. A comprehensive preceptor development program that leverages technology and preceptor networks will ensure preceptors have the skills to teach. The addition of an early hospital practice experience and inclusion of acute care content in the curriculum will improve the preparedness of learners. Creation of a user friendly "preceptor portal" on the Faculty's website will provide an enhanced customer oriented approach.

Implications: While these solutions will require substantial investment and the commitment of all parties involved, the result will be a modern, collaborative, and adaptable institutional experiential program. These solutions could have broad applicability to other jurisdictions in Canada. 


\section{Successful Medication Reconciliation Implementation in a Multi-site Acute Care Facility CSHP2D15}

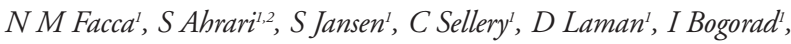
P Andress', R Runnels ${ }^{l, 2}, G$ Barbour ${ }^{l}, P$ Buschell ${ }^{l}, K$ Caldwell $^{\prime}$, C Channon', L Creasor', $M$ Davies' $^{l}, K$ Delamere' $^{l}, S$ Dhaliwal $^{l, 2}$, $M$ Douglas ${ }^{l}, M$ Goldszmidt',, Johnson ${ }^{I}, C$ Glover', S Lawson ${ }^{I}$, $S$ Lee $^{l, 2}$, D Lemairel, C Loblaw ${ }^{l}$, M Macpherson ${ }^{l}, M$ Martin $^{l}$,

L Neumann ${ }^{\prime}$, J Sumpton ${ }^{I}$, A Vandervecht ${ }^{\prime}$, J Yoon ${ }^{\prime}, R$ Walker ${ }^{l, 3}$

${ }^{1}$ London Health Sciences Centre, London, ON

${ }^{2}$ University of Waterloo, Waterloo, ON

${ }^{3}$ Western University, London, $\mathrm{ON}$

Background: Medication reconciliation is a required organizational practice by Accreditation Canada, and has been shown to reduce both medication errors at interfaces of care and prevent adverse drug events.

Description: Previous strategies to implement medication reconciliation in one of Canada's largest acute care teaching hospitals focused on admission and were limited in spread across all inpatient units. The goal of this project was to establish a medication reconciliation process at all interfaces of care.

Action: A strategy was devised to implement a new process and forms. The medication reconciliation project team engaged with various stakeholders to ensure successful adoption and implementation. Broad stakeholder communication strategies were used to inform and sustain change. The educational process included:

- Early general information sessions with frontline staff and leadership;

- Creation and distribution of tools and resources including workflows, web-based training modules, posters, and presentations;

- Unit specific planning, workflow reviews, and follow-up sessions led by the project team with clinical and clerical staff; and

- Unit specific educational sessions led by clinical educators for all frontline staff and by the project team for prescriber and pharmacy staff.

Evaluation: The project team and Health Records set up a process to abstract information from the medication reconciliation forms and generate reports that would assess staff and prescriber compliance.

Implication: Medication reconciliation was successfully implemented at admission, transfer, and discharge across all inpatient units of this institution as of June 2012. The process continues to be successful and sustainable. Institutions that are in the process of fully adopting medication reconciliation would benefit from using similar strategies to be successful in implementing this vital patient safety initiative.

For the table that goes with this abstract, please see Abstract Appendix, available online at www.cjhp-online.ca/index.php/cjhp/issue/view/ $100 /$ show Toc

\section{Facilitation of Medication Reconciliation by a Clinical Registered Pharmacy Technician in an Orthopedic Unit of a Community Hospital: A Pilot Project}

\section{CSHP2D15}

Lindsay Yoo, Jenny Chiu, Jocelyn Jackson, Mary Salgado-Corpuz, Yuen Chan-Lau, Joyce Choy, Edith Rolko

North York General Hospital, Toronto, ON, Canada

Rationale: A previous study at North York General Hospital identified delays in completion of a Best Possible Medication History (BPMH) to be associated with low rates of admission Medication
Reconciliation (MedRec) performed in surgical in-patients. In order to improve the admission MedRec rates, means to enhance the timeliness of BPMH completion were explored.

Description and Steps Taken: With the expanded scope of registered pharmacy technicians (RPhTs), our goal was to develop a BPMH $\mathrm{RPhT}$ role to facilitate the process of conducting a BPMH. We first performed a literature review and reviewed the experience of BPMH RPhTs at other institutions. Then, we examined the current BPMH and admission MedRec workflow in our hospital. Finally, we defined the role of the BPMH RPhT and developed a BPMH training and certification program for RPhTs. One RPhT was certified, and the BPMH RPhT role was piloted in the orthopedic unit for approximately 1 month.

Evaluation: During the 20 days on the unit, the BPMH RPhT interviewed 78 of $140(55.7 \%)$ patients, who were taking an average of 7 medications. The RPhT verified the availability of patient's own supply in $31(67.4 \%)$ of the 46 patients who were on non-formulary medications. Based on workload data, it was determined the RPhT saved the pharmacist 80 minutes per day in $\mathrm{BPMH}$ interviews and documentation. The RPhT prioritized and referred $67 \%$ of patients for further evaluation by the pharmacist (e.g. NF alternatives, need for influenza vaccine, etc). Comparing this period to the same a year ago, an increase from $57.3 \%$ to $87.9 \%$ in admission MedRec was observed.

Importance: The BPMH RPhT role helped facilitate admission MedRec and potentially saved pharmacists' time, thus allowing them to focus on other clinical activities. This initiative should be further evaluated and possibly expanded to other areas.

\section{Impact of a Multidisciplinary Program on Smoking Cessation Medication Use Patterns}

Koren Lui, Livia Vodenicar, Janice Ma

Canadian Armed Forces Health Services Group

Background: In May 2012, a multidisciplinary smoking cessation program was implemented at a Canadian Armed Forces medical clinic. The program aimed to enhance patient access and convenience to multidisciplinary support. Weekly clinics were conducted for selfreferred and medically referred patients. A pharmacist educated patients regarding available medication therapies (nicotine replacement therapy (NRT), varenicline, and bupropion) to aid the patients in making informed choices. A health promotions team member followed with an interactive teaching session on behaviour modification. After these group sessions, patients were individually assessed by a physician. The selected medication was dispensed in two-week allocations at the clinic's pharmacy.

Objective: To describe a multidisciplinary approach and its impact on smoking cessation medication use patterns.

Methods: A retrospective analysis was performed comparing dispensing records of patients who expressed interest in smoking cessation to a health care team member from June to December 2011 (pre-program implementation) and June to December 2012 (first 6 months after program implementation). Specifically: the selected therapy, completion of the 12 week therapy, and first to last fill intervals (as estimations of time spent in therapy).

Conclusion: Our new multidisciplinary approach was able to encourage more patients to initiate smoking cessation medication therapy, with an absolute increase in the number of people completing the 12 week therapy. Unexpectedly, there was a reduction in the proportion of people completing therapy and a marked decrease in the estimated time spent in therapy for those who did not complete it. Further 
follow-up and analysis are required to determine the clinical significance, and possible next steps to improve adherence.

For the table that goes with this abstract, please see Abstract Appendix, available online at www.cjhp-online.ca/index.php/cjhp/issue/view/ $100 /$ show Toc

\section{Impact des données probantes sur l'implantation des codes-barres en milieu hospitalier

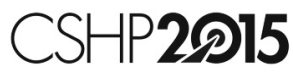

Aurélie Guérin', Denis Lebel', Jean-François Bussières ${ }^{l, 2}$ 'Département de pharmacie et Unité de recherche en pratique pharmaceutique, Centre hospitalier universitaire Sainte-Justine, Montréal, QC ${ }^{2}$ Faculté de pharmacie, Université de Montréal, Montréal, QC

Justification : On reconnaît les difficultés inhérentes à l'implantation de nouvelles technologies dans le circuit du médicament en hôpital. Certains auteurs considèrent qu'il faut en moyenne plus de 15 ans au réseau de la santé pour qu'un changement soit implanté à plus de 50\% en présence de données probantes.

Objectifs : Évaluer les délais entre la publication des meilleures preuves disponibles et l'implantation de lecteurs codes-barres pour l'identification du patient durant le processus d'administration du médicament au Canada.

Méthodologie et démarche de l'étude : Étude descriptive et rétrospective. À partir d'une revue documentaire sur Pubmed et Google, les meilleures preuves disponibles ont été identifiées à partir de revues (méta-analyses, revues systématiques, revues de littérature), les études descriptives issues de ces revues et les recommandations. Le taux d'implantation a été calculé à partir des données des rapports canadiens sur la pharmacie hospitalière de 1985-1986 à 2011-2012.

Résultats : Nous avons recensé une revue systématique (2010), trois revues de littérature (2003-2011), 16 études descriptives différentes issues de ces revues (2002-2008) et quatre recommandations (20042011). La première mention d'implantation de lecteurs codes-barres pour l'identification du patient durant le processus d'administration du médicament apparaît en 2001-2002. Son implantation demeure limitée au Canada, soit 3\% (2003-2004), 8\% (2005-2006), 3\% (2007-2008), 6\% (2009-2010) et 4\% (2011-2012). Compte tenu du faible taux d'implantation, on ne peut calculer le délai entre la publication des meilleures preuves et l'implantation à large échelle de lecteurs codes-barres pour l'identification du patient durant le processus d'administration du médicament au Canada.

Conclusion : Il existe peu de données sur les délais observés entre la publication des meilleures preuves disponibles et l'implantation de technologies. S'il existe des preuves de l'utilité des lecteurs codesbarres pour l'identification du patient durant le processus d'administration du médicament au Canada, il est raisonnable de penser qu'il faudra quelques années avant que cette technologie ne soit largement implantée au Canada.

\section{Impact des données probantes sur l'implantation des pompes intelligentes en milieu hospitalier}

Aurélie Guérin ${ }^{l}$, Denis Lebel ${ }^{l}$, Jean-François Bussières ${ }^{l, 2}$

${ }^{1}$ Département de pharmacie et Unité de recherche en pratique pharmaceutique, Centre hospitalier universitaire Sainte-Justine, Montréal, QC ${ }^{2}$ Faculté de pharmacie, Université de Montréal, Montréal, QC

Justification : On reconnaît les difficultés inhérentes à l'implantation de nouvelles technologies dans le circuit du médicament en hôpital.
Certains auteurs considèrent qu'il faut en moyenne plus de 15 ans au réseau de la santé pour qu'un changement soit implanté à plus de 50\% en présence de données probantes.

Objectifs : Évaluer les délais entre la publication des meilleures preuves disponibles et l'implantation de pompes intelligentes au Canada.

Méthodologie et démarche de l'étude: Étude descriptive et rétrospective. À partir d'une revue documentaire sur Pubmed et Google, les meilleures preuves disponibles ont été identifiées, soit les les revues (méta-analyses, revues systématiques, revues de littérature), les études descriptives issues de ces revues et les recommandations. Le taux d'implantation a été documenté à partir des données des rapports canadiens sur la pharmacie hospitalière de 1985-1986 à 2011-2012.

Résultats : Nous avons recensé une revue systématique (2007), trois revues de littérature (2008-2011), 13 études descriptives différentes issues de ces revues et trois recommandations (2009-2012). On s'intéresse à l'implantation des pompes intelligentes au Canada pour la première fois en 2007-2008. Son implantation demeure importante depuis, soit $61 \%$ (2007-2008), 68\% (2009-2010) et 75\% (20112012). Compte tenu du faible nombre de données probantes soutenant l'efficience des pompes intelligentes, on ne peut calculer, le délai entre la publication des meilleures preuves disponibles et l'implantation à large échelle des pompes intelligentes au Canada.

Conclusion : Il existe peu de données sur les délais observés entre la publication des meilleures preuves disponibles et l'implantation de technologies. La majorité des hôpitaux au Canada ont implanté des pompes intelligentes malgré l'absence de recommandations de sociétés savantes et d'études de bonne qualité. Cette implantation n'est pas étrangère au renouvellement des équipements.

\section{Impact des données probantes sur l'implantation de la réconciliation médicamenteuse en milieu hospitalier}

\section{CSHP2D15}

Aurélie Guérin ${ }^{I}$, Denis Lebel', Jean-François Bussières ${ }^{1,2}$ ${ }^{1}$ Département de pharmacie et Unité de recherche en pratique pharmaceutique, Centre hospitalier universitaire Sainte-Justine, Montréal, QC ${ }^{2}$ Faculté de pharmacie, Université de Montréal, Montréal, QC

Justification : Les différentes étapes de transition de soins du patient à l'hôpital sont à risque majeur d'erreurs médicamenteuses. On reconnaît par ailleurs les difficultés inhérentes à l'implantation de nouveaux processus. Certains auteurs considèrent qu'il faut en moyenne plus de 15 ans au réseau de la santé pour qu'un changement soit implanté à plus de 50\% en présence de données probantes.

Objectifs : Évaluer les délais entre la publication des meilleures preuves disponibles et l'implantation de la réconciliation médicamenteuse au Canada.

Méthodologie et démarche de l'étude : Étude descriptive et rétrospective. À partir d'une revue documentaire sur Pubmed et Google, nous avons identifié les meilleures preuves disponibles, soit les revues (méta-analyses, revues systématiques, revues de littérature), les études descriptives issues de ces revues et les recommandations. Le taux d'implantation a été documenté à partir des données des rapports canadiens sur la pharmacie hospitalière de 1985-1986 à 2011-2012.

Résultats : Nous avons recensé 10 revues systématiques (2009-2013), une revue de littérature (2005), 70 études descriptives issues de ces revues (1993-2012) et cinq recommandations (2006-2013). On s'intéresse au préalable à l'implantation de l'histoire médicamenteuse dès 1985-1986 au Canada. L'implantation était alors de 6\%. Le terme 
de réconciliation médicamenteuse apparaît en 2005-2006. En 20112012, son implantation était, respectivement, de $85 \%$ à l'admission, $47 \%$ au transfert et de $44 \%$ au départ. En tenant compte du processus complet de réconciliation médicamenteuse, le délai entre la publication des meilleures preuves disponibles et l'implantation à large de la réconciliation médicamenteuse au Canada n'est que d'une année.

Conclusion : Il existe peu de données sur les délais observés entre la publication des meilleures preuves disponibles et l'implantation de nouveaux processus. L'ajout de la réconciliation médicamenteuse aux pratiques organisationnelles requises d'Agrément Canada n'est sans doute pas étranger au court délai d'implantation de cette pratique.

\section{Prescribing Patterns and Safety of Intramuscular Olanzapine in Hospitalized Elderly Patients}

Amy Wong', Kam-Tong Yeung ${ }^{2}$, Fran Wolfe, Monica Lee ${ }^{2}$

${ }^{1}$ Leslie Dan Faculty of Pharmacy, University of Toronto, ON

${ }^{2}$ North York General Hospital, Toronto, ON

Background: Intramuscular (IM) olanzapine is sometimes used to manage acute behavioural and psychological symptoms in hospitalized elderly patients with dementia or delirium. However, its use for this indication is off-label and safety concerns remain.

Objectives: To identify prescribing patterns of IM olanzapine and associated adverse effects, and to compare the results to those from a case series of elderly patients who received the drug when it first became available for these patients in 2008 .

Methods: We conducted a retrospective chart review of all in-patients aged 65 years or older who received at least one dose of IM olanzapine between November 2010 and December 2012. Patient demographics, comorbidities, IM olanzapine treatment details, concurrent medications, and documented adverse effects were analyzed.

Results: Seventy-six patients were identified to have received at least one dose of IM olanzapine. Of the 100 orders, 52 (52\%) were written by psychiatrists and $32(32 \%)$ by geriatricians. The most common indications included agitation (64 individuals, 84\%) and refusal or inability to take oral medications (23 individuals, 30\%). The mean dose given at one time was $4.2 \mathrm{mg}( \pm 2.6 \mathrm{mg})$. Eighteen $(24 \%)$ individuals experienced constipation, 15 (20\%) experienced lethargy and $11(15 \%)$ experienced drowsiness. Serious adverse effects observed included 9 cases $(12 \%)$ of hypotension, 3 (4\%) falls within 24 hours post dose, and $1(1 \%)$ case of aspiration pneumonia. Compared to the previous case series, prescribing patterns remained the same with respect to predominant prescribers and indications. Lethargy and drowsiness continued to be commonly experienced adverse effects while the incidence of falls, infections and extra-pyramidal symptoms was lower in the current cohort.

Conclusions: In the acute setting, psychiatrists and geriatricians may prescribe IM olanzapine for behavioural symptoms in elderly patients. Commonly experienced adverse effects include lethargy, drowsiness and constipation. Close monitoring is the key to ensuring safe use.

\section{Optimizing Pharmacotherapy in a Geriatric Day Hospital: A Medication Use and Cost Analysis CSHP2D15}

Barbara Farrell ${ }^{1,2}$, Evan Steed ${ }^{l, 2}$, Danielle Paes ${ }^{1,2}$, Salima Shamjï, Veronique French Merkley ${ }^{I}$, Anne Monahan ${ }^{I}$

${ }^{\prime}$ Bruyere Continuing Care, University of Ottawa, Ottawa, ON

${ }^{2}$ University of Waterloo, Waterloo, $O N$
Rationale: Polypharmacy in the elderly is associated with adverse drug reactions, emergency room visits, hospitalization and cost. Deprescribing and interprofessional team interventions are important approaches to reducing polypharmacy, pill burden and cost.

Objective: To determine impact - on medication use and cost to a provincial drug program - of interprofessional medication review and interventions aimed at optimizing pharmacotherapy for patients admitted to a 12-week Geriatric Day Hospital program.

Study Design and Methods: Pre- and post-intervention medication numbers (prescription \& non-prescription), pill burden (number of oral doses per day) and Ontario Drug Benefit (ODB) acquisition drug costs (using lowest priced generic drug - excluding 'as needed' medications and those not covered by ODB) for 8 patient cases accepted for publication. Calculations independently verified by a second researcher. Daily and yearly ODB program cost-savings estimates and projections made using annual GDH admission rates.

Results: Average daily per patient medication use was reduced by 4.4 medications (from 17.5 to 13.1 ) and average daily pill burden was reduced by 5.2 doses (from 21.8 to 16.6). Estimated per patient medication cost savings were $\$ 2.55$ per day, with annual cost savings projected at $\$ 930$ per patient. If extrapolated to the 350 patients admitted to the GDH each year, medication review and interventions aimed at optimizing pharmacotherapy could result in savings of approximately $\$ 325,000$ in medication costs to ODB annually. Limitations include highly selected patient cases, and inclusion of only some costs related to medication use.

Conclusion: Inter-professional medication review and interventions during GDH admissions reduced medication use and pill burden with important projected savings. Future economic modeling should include costs relating to medications not covered by ODB, mark-up and dispensing fees, pharmacist time spent and benefits of pharmacotherapy optimization (e.g. reduced hospitalization, falls etc.).

\section{Home Care Pharmacy Services: A Demonstration Project}

\section{CSHP2D15}

Douglas Doucette', Terry Morrissey², Ann Nickerson ${ }^{2}$

${ }^{1}$ Regional Pharmacy Services, Horizon Health Network, NB

${ }^{2}$ Extra-Mural Program, Moncton Area, Horizon Health Network, NB

Rationale: In 2008 clinical pharmacy services were introduced to home care clients in the Extra-Mural Program (EMP) in collaboration with a multidisciplinary team. A second phase of the demonstration project evaluated the pharmacist's role in providing a feasible and sustainable service to EMP clients. The project was intended to align pharmacy services with EMP needs for a designated geographical area, avoid duplication of existing services and obtain meaningful outcome measures.

Description of Project: This project evaluated the effectiveness of the pharmacy services provided to EMP clients over a 12-month period in 2012-2013. Clients referred to the pharmacist had at least 2 previous attempts by health care professionals to resolve the high-risk symptoms or medication-related problems, and were classified by the clients' likelihood for adverse outcome or admission to hospital. Once accepted on the pharmacy caseload the pharmacist conducted a home visit to establish a care plan and provided additional follow-up visits or phone calls as required. Clinical and quality measures of the medication-related issues identified were used to assess the impact of the interventions. 


\section{PPC 2014 POSTER ABSTRACTS / RÉSUMÉS DES AFFICHES DE LA CPP 2014}

Project Evaluation: Working with clients and healthcare team members to establish goals of therapy, the pharmacist was able to fully or partially resolve 305 of 330 (92.4 percent) of clients' medicationrelated issues. This result is even more compelling considering many clients were deemed high/urgent priority based on their symptoms, quality of life, or risk of hospital admission. Although often requested to investigate 1 unresolved symptom or issue, clients seen by the pharmacist had a median of 5 medication-related issues. The percent of clients on the pharmacy caseload admitted to hospital (per quarter) ranged from 21 to 50 and often involved consultation between pharmacist and attending physician.

Summary: A home care pharmacist was effectively able to resolve clients' high-risk medication-related issues that were unable to be resolved by other healthcare team members.

\section{Impact des données probantes sur l'implantation des prescripteurs électroniques en milieu hospitalier}

\section{CSHP2D15}

Aurélie Guérin ${ }^{l}$, Denis Lebel ${ }^{l}$, Jean-François Bussières ${ }^{l, 2}$

'Département de pharmacie et Unité de recherche en pratique pharmaceutique, Centre hospitalier universitaire Sainte-Justine, Montréal, QC ${ }^{2}$ Faculté de pharmacie, Université de Montréal, Montréal, QC

Justification : On reconnaît les difficultés inhérentes à l'implantation de nouvelles technologies dans le circuit du médicament en hôpital. Certains auteurs considèrent qu'il faut en moyenne plus de 15 ans au réseau de la santé pour qu'un changement soit implanté à plus de 50\% en présence de données probantes.

Objectifs : Évaluer les délais entre la publication des meilleures preuves disponibles et l'implantation de prescripteurs électroniques au Canada.

Méthodologie et démarche de l'étude : Étude descriptive et rétrospective. À partir d'une revue documentaire sur Pubmed et Google, les meilleures preuves disponibles ont été identifiées, les revues (méta-analyses, revues systématiques, revues de littérature), les études descriptives issues de ces revues et les recommandations. Le taux d'implantation a été documenté à partir des données des rapports canadiens sur la pharmacie hospitalière de 1985-1986 à 2011-2012.

Résultats : Nous avons recensé trois méta-analyses (2008-2013), 13 revues systématiques (2003-2013), quatre revues de littérature (20032010), 198 études descriptives issues de ces revues (1984-2011) et quatre recommandations (2010-2011). On s'intéresse à l'implantation de prescripteurs électroniques au Canada pour la première fois en 2001-2002. Son implantation demeure limitée, soit 7\% (2001-2002), 5\% (2003-2004), 6\% (2005-2006), 5\% (2007-2008), 8\% (2009$2010)$ et $8 \%$ (2011-2012). Compte tenu du faible taux d'implantation, on ne peut calculer le délai entre la publication des meilleures preuves disponibles et l'implantation à large échelle de prescripteurs électroniques au Canada.

Conclusion : Il existe peu de données sur les délais observés entre la publication des meilleures preuves disponibles et l'implantation de technologies. Le délai d'implantation des prescripteurs électroniques n'est peut-être pas étranger aux coûts, à la complexité de l'implantation et aux preuves limitées dans la littérature.
Impact des données probantes sur l'implantation d'aides à la décision clinique pour les prescripteurs électroniques en milieu hospitalier

\section{CSHP2D15}

Aurélie Guérin ${ }^{1}$, Denis Lebel', Jean-François Bussières ${ }^{1,2}$

${ }^{1}$ Département de pharmacie et Unité de recherche en pratique pharmaceutique, Centre hospitalier universitaire Sainte-Justine, Montréal, QC ${ }^{2}$ Faculté de pharmacie, Université de Montréal, Montréal, QC

Justification : On reconnait les difficultés inhérentes à l'implantation de nouvelles technologies dans le circuit du médicament en hôpital. Certains auteurs considèrent qu'il faut en moyenne plus de 15 ans au réseau de la santé pour qu'un changement soit implanté à plus de 50\% en présence de données probantes.

Objectifs : Évaluer les délais entre la publication des meilleures preuves disponibles et l'implantation d'aides à la décision clinique pour les prescripteurs électroniques au Canada.

Méthodologie et démarche de l'étude : Étude descriptive et rétrospective. À partir d'une revue documentaire sur Pubmed et Google, les meilleures preuves disponibles ont été identifiées, les revues (méta-analyses, revues systématiques, revues de littérature), les études descriptives issues de ces revues et les recommandations. Le taux d'implantation a été documenté à partir des données des rapports canadiens sur la pharmacie hospitalière de 1985-1986 à 2011-2012.

Résultats : Nous avons recensé 3 méta-analyses et revues systématiques (1999-2013), 17 revues systématiques (1998-2013), sept revues de littérature (1994-2012) et deux rapports (2011,2012), 341 études descriptives différentes issues des revues (1957-2012) et une recommandation (2006). On s'intéresse à l'implantation d'aides à la décision clinique pour les prescripteurs électroniques au Canada pour la première fois en 2001-2002. Son implantation évolue progressivement, soit 33\% (2001-2002), 14\% (2003-2004), 75\% (2005-2006), $58 \%$ (2009-2010) et 75\% (2011-2012). Le délai calculé entre la publication des meilleures preuves et l'implantation à large échelle de prescripteurs électroniques au Canada était de 5 ans, soit entre 2000 et 2005 .

Conclusion : Il existe peu de données sur les délais observés entre la publication des meilleures preuves disponibles et l'implantation de technologies. On reconnaît que le changement est difficile et sa gestion complexe, particulièrement au sein de grandes organisations. Il a fallu 5 années pour implanter à large échelle des aides à la décision clinique pour les prescripteurs électroniques au Canada; le nombre de prescripteurs électroniques implanté demeure toutefois extrêmement limité. 